\title{
Taxation and Corporate Investment: A q-Theory Approach
}

THE PAST DECADE has witnessed increasing concern over the level of business capital formation in the United States. By some measures there has been a sharp decline in the rate of capital formation, accompanied by a drastic reduction in the stock market's valuation of corporate assets. Measured in 1981 dollars, the Dow Jones average stood at almost 2000 in 1965. This decline in investment and market valuation has occurred in conjunction with the substantial changes in the effective taxation of capital income brought on by inflation. Although causal links among these developments have not been clearly established, a consensus in favor of some sort of tax incentive for business capital formation has emerged. At present, however, there is no solid basis for assessing the likely impact of any given menu of tax policies on the level of investment or on the distribution of income.

This paper presents an analysis of the effects of tax policy on capital accumulation and valuation based on James Tobin's $q$ theory of investment. As Tobin has explained, aggregate investment can be expected to

I am indebted to James Kahn and Andrei Shleifer for research assistance. I have benefited from discussions with Martin Feldstein, Stanley Fischer, David Lipton, Marcia Moore, James Poterba, and participants at the Brookings panel. This research was partially supported by the National Bureau of Economic Research as part of its project on capital formation. 
depend in a stable way on $q$, the ratio of the stock market valuation of existing capital to its replacement cost. For example, increases in the rate of return on physical capital raise its market value and cause increased investment until equilibrium is restored. Although models linking the stock market to investment have been estimated, they have not previously been used to examine the impact of tax policies. The basic idea underlying the approach taken here can be described quite simply. It is generally assumed that the stock market valuation of corporate capital represents the present value of its future dividend stream. In the model of this paper, the effects of tax changes on future profits are used to estimate the impact of those changes on the stock market. These estimates in turn are used as a basis for gauging the impact of the tax changes on capital formation. This approach, working through $q$, can provide estimates of the effects of policy announcements and of personal tax reforms as well as estimates of the distributional impact of alternative reforms. A distinct feature of the model developed here is that it is rooted in a microeconomic theory that integrates the interests of the corporation and its shareholders.

The paper begins with a review of recent trends in the rate of capital formation and in certain key investment determinants. Data from the recently revised national income and product accounts are used to examine the performance of real business fixed investment over the past three decades. Despite widespread concern about capital formation, the ratio of real gross fixed nonresidential investment to GNP has, if anything, been high in the 1970s relative to postwar norms. The ratio of capital to output has actually risen since 1970 . Other indicators suggest more cause for concern, however. Net investment, after adjustment for investment mandated by regulation, shows a dramatic decline in the past decade. This decline is of particular concern because the sharp rise in energy prices and the high rate of labor force growth called for increases in the rate of investment. The data also indicate that the tax burden on corporate capital income flowing to the holders of equity has not increased greatly during the 1970s. Reductions in statutory rates have offset the impact of inflation.

The $q$ theory of investment underlying the estimates of tax policy impacts is described in the second section of the paper. It is shown that, under certain restrictive assumptions, the value of $q$, as measured in financial markets, can be closely linked to the shadow price of new capital in a microeconomic theory of investment in the presence of adjustment 
costs. The way in which particular tax policies affect investment is also examined. Both the investment and distributional effects of tax incentives depend critically on the form they take. Through judicious combination of tax policies, it is possible to spur investment while minimizing the windfall of income or wealth to existing corporate shareholders. These windfalls have important distributional consequences because almost all corporate shares are beneficially owned by wealthy individuals.

In the third part of the paper the empirical procedures for evaluating investment incentives are described. Investment equations using "taxadjusted $q$ " as an explanatory variable are shown to have somewhat more explanatory power than equations that rely on the $q$ variable that is customarily used. Tax adjustments also provide a partial explanation for the anomalously low values of $q$ that have occurred recently. The assumptions about production technology and corporate financial policy that underlie the simulations of tax changes are also discussed.

In the fourth part of the paper I examine the effects of changes in real tax rates, either legislated or caused by inflation in the absence of indexation of the tax system. The analysis indicates that if changes in tax policy or inflation do not affect the real after-tax rate of return required by individual investors, inflation is likely to have a substantial negative impact on both investment and the stock market. Statutory reforms are also likely to have important effects. The elimination of taxes on capital gains would, for example, raise capital intensity by 18 percent in the long run. However, the empirical estimates suggest that the adjustment process is much slower than is usually assumed, with a half-life of more than a decade. The calculations also illustrate the wide range of distributional consequences of different incentives.

Most analyses of the impact of tax policy on investment, including this one, assume that tax reforms have no effect on the real after-tax rate of return required by investors in the corporate sector. This is equivalent to postulating a perfectly elastic supply of funds to the business sector. It is argued in the fifth part of the paper that this assumption is plausible, both because the business sector is small relative to the entire capital market and because the overall savings rate is likely to be sensitive to the after-tax rate of return. The analysis of changes in real tax rates induced by inflation requires some modification of this assumption since inflation affects the return to investment in all sectors, not just the corporate sector. The empirical evidence, although weak, is consistent with the assumption of a 
constant real required rate of return. Even small permanent changes in the required rate of return have large estimated impacts on the level of investment. This sensitivity suggests that the determinants of the required rate might be an important topic for further research.

\section{Trends in the Rate of Business Capital Formation}

In this section, I examine trends in the rate of nonresidential capital formation using data from the recently revised national income and product accounts, which significantly increased the estimated rate of investment compared with previous data on those accounts. Alternative indicators of trends in capital formation can be constructed from the accounts data, and these provide quite different pictures of how these trends changed.

\section{HISTORICAL COMPARISONS}

Various measures of the rate of investment are shown in table 1. Columns 1 and 2 suggest that there is little cause for concern about capital formation during the 1970s. The share of nonresidential investment in GNP was larger than it was in either of the other postwar decades. The ratio of the net capital stock to potential output was higher at the end of the 1970s than at the beginning. The rate of growth of this ratio, however, does show a substantial decline. ${ }^{1}$

Column 3 tracks the performance of net investment. ${ }^{2}$ This concept is appropriate to the analysis of capital accumulation since interest centers on the rate of increase of productive capacity. The net investment measure indicates a significant investment shortfall during the late 1970s. The net investment share in GNP averaged only 2.6 percent between 1975 and 1979 compared with 3.1 percent during the entire $1948-79$ period. This

1. In standard models with labor-augmenting change, the capital-output ratio is an indicator of capital intensity. If, however, technical change is not strictly laboraugmenting, the ratio will trend through time.

2. The calculation of net investment is obviously sensitive to assumptions about depreciation. These calculations are based on straight-line depreciation with lifetimes that are 0.85 of those of the Internal Revenue Service Bulletin F (1942). The results are similar using alternative depreciation measures, except that rates of net investment are much lower if exponential depreciation is assumed. 
occurred despite the cyclical expansion during this interval. The decline in net investment relative to gross investment reflects a rising capitaloutput ratio, which increases the share of depreciation in GNP, and a shift in the composition of investment toward equipment and away from structures.

Although investment in pollution control and safety may improve health and general welfare, it does not augment productive capacity or contribute to GNP. It is therefore appropriate to subtract much of this investment in assessing investment performance during the late 1970s. Only data on direct pollution control expenditures are available. When these expenditures are subtracted, as shown in column 4, the data show significant recent weakness. As column 5 shows, the rate of investment by this measure was lower than in any other postwar interval, and was only three-quarters of its postwar average rate. The rate of growth of the capital stock itself also shows a significant decline relative to earlier experience. Indeed, the rate of net capital formation recently fell below the rate in the late 1950s, when a deficiency in capital formation was almost universally acknowledged. The ratio of real capital to employment actually declined over the 1974-79 period.

The adequacy of business investment cannot be assessed by simple comparisons of recent and historical experience; a variety of factors affect the desirable level of investment. There have been several changes in recent years that may have significantly lowered the optimal level of business investment. The coming of age of the baby-boom generation probably should have led to a redirection of investment expenditures from business investment toward housing. Conceivably, the productivity slowdown could reflect a slowdown in technical change that has reduced the optimal level of investment. Indeed, it may be that the observed decline in investment simply represents a return to normalcy after aberrant behavior in the late $1960 \mathrm{s.}^{3}$

There are, however, two major factors that should have led to increases in the measured rate of net investment during the 1970s. They suggest that the moderate declines actually reflect a substantial shortfall relative

3. It does not appear that the low level of investment during the 1970s is the result of cyclical factors. In earlier work, I reported cyclically adjusted rates of investment, which demonstrated that only a negligible fraction of the shortfall can be traced to cyclical factors. See Lawrence H. Summers, "Tax Policy and Corporate Investment," Conference on Supply Side Economics, Federal Reserve Bank of St. Louis, forthcoming. 
Table 1. Postwar Investment Trends, 1948-80 and Selected Periods ${ }^{\mathrm{a}}$

\begin{tabular}{|c|c|c|c|c|c|}
\hline $\begin{array}{l}\text { Year and } \\
\text { period }\end{array}$ & $\begin{array}{c}\text { Share } \\
\text { of gross } \\
\text { investment } \\
\text { in GNP } \\
\text { (1) }\end{array}$ & $\begin{array}{l}\text { Ratio of } \\
\text { capital } \\
\text { to output } \\
\quad(2)\end{array}$ & $\begin{array}{c}\text { Share } \\
\text { of net } \\
\text { investment } \\
\text { in GNP } \\
\text { (3) }\end{array}$ & $\begin{array}{l}\text { Share } \\
\text { of net } \\
\text { productive } \\
\text { investment } \\
\text { in GNPc } \\
(4)\end{array}$ & $\begin{array}{c}\text { Annual } \\
\text { growth } \\
\text { rate of } \\
\text { net capital } \\
\text { stock } \\
\text { (percent) } \\
(5)\end{array}$ \\
\hline 1948 & 0.104 & 0.691 & 0.044 & 0.044 & 8.0 \\
\hline 1949 & 0.093 & 0.693 & 0.030 & 0.030 & 4.7 \\
\hline 1950 & 0.093 & 0.697 & 0.032 & 0.032 & 5.0 \\
\hline 1951 & 0.091 & 0.700 & 0.031 & 0.031 & 5.0 \\
\hline 1952 & 0.087 & 0.697 & 0.025 & 0.025 & 3.9 \\
\hline 1953 & 0.090 & 0.699 & 0.028 & 0.028 & 4.3 \\
\hline 1954 & 0.090 & 0.698 & 0.024 & 0.024 & 3.4 \\
\hline 1955 & 0.093 & 0.704 & 0.029 & 0.029 & 4.3 \\
\hline 1956 & 0.097 & 0.711 & 0.032 & 0.032 & 4.5 \\
\hline 1957 & 0.097 & 0.716 & 0.030 & 0.030 & 4.1 \\
\hline 1958 & 0.087 & 0.707 & 0.018 & 0.018 & 2.3 \\
\hline 1959 & 0.088 & 0.703 & 0.021 & 0.021 & 2.8 \\
\hline 1960 & 0.091 & 0.701 & 0.024 & 0.024 & 3.2 \\
\hline 1961 & 0.088 & 0.697 & 0.021 & 0.021 & 2.8 \\
\hline 1962 & 0.090 & 0.697 & 0.025 & 0.025 & 3.5 \\
\hline 1963 & 0.090 & 0.696 & 0.026 & 0.026 & 3.6 \\
\hline 1964 & 0.094 & 0.700 & 0.031 & 0.031 & 4.4 \\
\hline 1965 & 0.105 & 0.715 & 0.042 & 0.042 & 6.0 \\
\hline 1966 & 0.110 & 0.734 & 0.047 & 0.047 & 6.7 \\
\hline 1967 & 0.104 & 0.746 & 0.041 & 0.039 & 5.4 \\
\hline 1968 & 0.103 & 0.757 & 0.039 & 0.038 & 5.1 \\
\hline 1969 & 0.107 & 0.770 & 0.041 & 0.039 & 5.4 \\
\hline 1970 & 0.105 & 0.775 & 0.035 & 0.033 & 4.2 \\
\hline 1971 & 0.100 & 0.773 & 0.029 & 0.026 & 3.3 \\
\hline 1972 & 0.102 & 0.775 & 0.031 & 0.028 & 3.9 \\
\hline 1973 & 0.110 & 0.786 & 0.040 & 0.036 & 5.2 \\
\hline 1974 & 0.109 & 0.792 & 0.035 & 0.031 & 4.3 \\
\hline 1975 & 0.097 & 0.783 & 0.019 & 0.015 & 2.1 \\
\hline 1976 & 0.097 & 0.774 & 0.020 & 0.016 & 2.2 \\
\hline 1977 & 0.103 & 0.772 & 0.026 & 0.023 & 3.1 \\
\hline 1978 & 0.107 & 0.774 & 0.031 & 0.028 & 3.7 \\
\hline 1979 & 0.110 & 0.781 & 0.033 & 0.030 & 4.0 \\
\hline 1980 & 0.107 & n.a. & n.a. & n.a. & n.a. \\
\hline
\end{tabular}


Table 1 (continued)

\begin{tabular}{cccccc}
\hline & $\begin{array}{c}\text { Share } \\
\text { of gross } \\
\text { investment } \\
\text { in GNP } \\
(1)\end{array}$ & $\begin{array}{c}\text { Ratio of } \\
\text { capital } \\
\text { to output } \\
(2)\end{array}$ & $\begin{array}{c}\text { Share } \\
\text { of net } \\
\text { investment } \\
\text { in GNP } \\
\begin{array}{c}\text { Year and } \\
\text { period }\end{array}\end{array}$ & $\begin{array}{c}\text { Share } \\
\text { of net } \\
\text { productive } \\
\text { investment } \\
\text { in GNP } \\
(4)\end{array}$ & $\begin{array}{c}\text { Annual } \\
\text { growth } \\
\text { rate of } \\
\text { net capital } \\
\text { stock } \\
\text { (percent) } \\
\text { (5) }\end{array}$ \\
\hline Average & & & & & \\
$1948-79$ & 0.098 & 0.731 & 0.031 & 0.029 & 4.2 \\
$1950-54$ & 0.090 & 0.698 & 0.028 & 0.028 & 4.3 \\
$1955-59$ & 0.092 & 0.708 & 0.026 & 0.026 & 3.6 \\
$1960-64$ & 0.091 & 0.698 & 0.025 & 0.025 & 3.7 \\
$1965-69$ & 0.106 & 0.744 & 0.042 & 0.041 & 5.7 \\
$1970-74$ & 0.105 & 0.780 & 0.034 & 0.031 & 4.2 \\
$1975-79$ & 0.103 & 0.777 & 0.026 & 0.022 & 3.0 \\
\hline
\end{tabular}

Source: U.S. Department of Commerce, Bureau of Economic Analysis, and Council of Economic Advisers.

n.a. Not available.

a. Refers to real nonresidential fixed investment and capital stock. Calculation of net figures is based on straight-line depreciation.

b. The ratio of net fixed nonresidential capital stock to potential output, as calculated by the Council of Economic Advisers.

c. Calculated by subtracting direct pollution control expenditures from investment.

to what would have been socially desirable. First, the increase in energy prices and other supply shocks that occurred almost certainly have hastened the obsolescence of some capital goods. Thus depreciation has been understated in the national accounts and net investment overstated. It is difficult to gauge the magnitude of this effect, but there is some evidence that it is likely to be substantial; conservative estimates place it near 0.5 percent of GNP a year. ${ }^{4}$ If this estimate is correct, the true rate of productive capital formation during the past five years has been only 1.7 percent of GNP, representing about half its rate during the 1960s. In addition, the energy shocks should have provided an extra stimulus to direct energy investment, a development that should also have raised overall investment.

A second factor that should have raised investment relative to recent and historical experience is the recent rapid rate of growth in labor sup-

4. Martin Baily's paper in this issue suggests this effect is very important. Ronald G. Ridker and William D. Watson estimate 0.5 percent of GNP as a lower limit on the increased turnover of the capital stock due to higher energy prices. See their To Choose a Future: Resource and Environmental Consequences of Alternative Growth Paths (Johns Hopkins University Press, 1980). 
ply. The volume of private business employment rose by an average of 1.3 percent a year between 1949 and 1974, but by 3.1 percent a year between 1974 and 1979. The growth rate of total hours of work showed an even more dramatic increase. This increase in the rate of growth of labor input might have been expected to lead to an increase in the rate of capital input. In fact, the decline in the rate of growth of the capital stock has been so large that the ratio of real capital to employment actually declined over the $1974-79$ period. $^{5}$

Before turning to an examination of what has happened to the effective taxation of equity income of corporations, it is important to stress that the recent performance of investment does not necessarily have any implications for tax policy. The optimum level of investment depends on complex social, economic, and ethical factors, and not on some arbitrary historical norm. ${ }^{6}$

\section{TAXATION OF CORPORATE CAPITAL INCOME}

The lion's share of nonresidential investment in the United States is undertaken by corporations. As is now well understood, inflation leads to substantial nonneutralities in the taxation of corporate source income. In this section a brief effort is made to determine what has happened to the effective tax rate at all levels of the tax system on the real equity income received by investors in the corporate sector. These estimates capture the effects of inflation, statutory reductions in the corporate tax rate, increases in the investment tax credit, and rapid depreciation allowances.

Table 2 provides estimates of inflation-adjusted corporate equity income and various components of the tax on it. ${ }^{7}$ Inflation-adjusted income, shown in column 1 , is calculated by adjusting profits in the national income and product accounts for the effects of inflation on the value of firms' debts. This is done by adding to profits the rate of inflation multi-

5. See Economic Report of the President, January 1981, table 9, p. 71.

6. For an analysis of the case for spurring business investment, see Summers, "Tax Policy and Corporate Investment."

7. A more extensive discussion of these issues may be found in Martin Feldstein and Lawrence H. Summers, "Inflation and the Taxation of Capital Income in the Corporate Sector," National Tax Journal, vol. 32 (December 1979), pp. 445-70. See also Martin Feldstein and James Poterba, "State and Local Taxes and the Rate of Return on the Non-Financial Corporate Capital," Working Paper 508 (National Bureau of Economic Research, July 1980). 
Table 2. Effective Taxation of Corporate Equity Income, 1953-79a

Billions of dollars unless otherwise specified

\begin{tabular}{|c|c|c|c|c|c|}
\hline Year & $\begin{array}{l}\text { Inflation- } \\
\text { adjusted } \\
\text { corporate } \\
\text { profits } \\
\text { (1) }\end{array}$ & $\begin{array}{l}\text { Corporate } \\
\text { taxes } \\
(2)\end{array}$ & $\begin{array}{l}\text { Dividend } \\
\text { taxes } \\
(3)\end{array}$ & $\begin{array}{l}\text { Capital } \\
\text { gains } \\
\text { taxes } \\
(4)\end{array}$ & $\begin{array}{c}\text { Total } \\
\text { tax rate } \\
\text { (percent) } \\
(5)\end{array}$ \\
\hline 1953 & 30.6 & 18.5 & 2.8 & 0.5 & 71.5 \\
\hline 1954 & 28.9 & 15.6 & 2.9 & 0.4 & 65.6 \\
\hline 1955 & 38.6 & 20.2 & 3.4 & 0.7 & 62.7 \\
\hline 1956 & 36.7 & 20.1 & 3.5 & 0.7 & 66.4 \\
\hline 1957 & 36.4 & 19.1 & 3.6 & 1.1 & 65.0 \\
\hline 1958 & 31.2 & 16.2 & 3.5 & 0.7 & 65.7 \\
\hline 1959 & 41.0 & 20.7 & 3.8 & 0.9 & 61.8 \\
\hline 1960 & 38.5 & 19.2 & 3.9 & 0.8 & 62.2 \\
\hline 1961 & 38.9 & 19.5 & 4.0 & 0.7 & 62.0 \\
\hline 1962 & 46.6 & 20.6 & 4.2 & 1.1 & 55.5 \\
\hline 1963 & 52.3 & 22.8 & 4.6 & 1.2 & 54.7 \\
\hline 1964 & 58.8 & 24.0 & 4.6 & 1.4 & 51.0 \\
\hline 1965 & 69.3 & 27.2 & 5.0 & 1.8 & 49.0 \\
\hline 1966 & 75.5 & 29.5 & 5.4 & 2.2 & 49.3 \\
\hline 1967 & 71.9 & 27.7 & 5.8 & 2.1 & 49.4 \\
\hline 1968 & 79.3 & 33.4 & 6.5 & 2.6 & 53.6 \\
\hline 1969 & 75.2 & 33.1 & 6.4 & 3.9 & 57.6 \\
\hline 1970 & 61.6 & 27.0 & 6.1 & 3.7 & 59.6 \\
\hline 1971 & 70.9 & 29.8 & 6.1 & 4.1 & 56.3 \\
\hline 1972 & 80.9 & 33.6 & 6.3 & 4.1 & 54.4 \\
\hline 1973 & 93.8 & 40.0 & 6.5 & 6.1 & 56.1 \\
\hline 1974 & 93.7 & 42.0 & 6.7 & 10.0 & 62.7 \\
\hline 1975 & 108.4 & 41.2 & 8.1 & 9.6 & 54.3 \\
\hline 1976 & 123.6 & 52.6 & 9.7 & 7.9 & 56.8 \\
\hline 1977 & 148.1 & 59.4 & 10.7 & 10.3 & 54.4 \\
\hline 1978 & 165.9 & 67.3 & 12.2 & 12.4 & 55.4 \\
\hline 1979 & 180.0 & 69.7 & 13.0 & 12.1 & 52.7 \\
\hline
\end{tabular}

Source: Calculations by the author, as described in the text. a. Refers to nonfinancial corporate business. 
plied by the book value of indebtedness. The profits are already adjusted for the effects of historical cost depreciation and FIFO (first in, first out) inventory accounting. Three components of the taxation of this income need to be considered. Profits tax liabilities are shown in column 2 . These are taken directly from the national income and product accounts data. The estimates of dividend taxes, reported in column 3, are based on an examination of the tax rates faced by different categories of corporate stockholders. ${ }^{8}$ The average tax rate varies relatively little over the sample period from 40 percent in 1955 to 31 percent in $1973 .{ }^{9}$ Fluctuations reflect both changing tax regulations and movements in the composition of equity ownership. Column 4 presents estimates of accrued capital gains taxes derived by assuming that accrued capital gains are equal to the sum of retained earnings and the nominal appreciation of the capital stock, measured at replacement cost. ${ }^{10}$ The calculation of effective capital gains rates, like that of dividend tax rates, involves averaging over different categories of investors. The estimates take account of the deferral of tax payments until realization and the fact that many capital gains are not taxed because of the death of the share owner. These features lead to a very low rate of capital gains taxation, averaging about 5 percent over the sample period.

Column 5 of the table shows the effective tax rate on equity income when all these taxes are added together. Two features of the numbers merit comment. First, the tax rate is much lower than estimates presented by Martin Feldstein and me of the total tax rate on all capital income arising in the corporate sector. This is because the tax rate on corporate income paid to bondholders, which is included in our earlier calculations

8. The calculation explicitly recognizes the existence of a variety of institutions such as pension plans, Individual Retirement Accounts, and Keogh plans, which allow dividends to escape taxation.

9. This tax rate is calculated as the ratio of estimated tax collections to reported dividends. The estimate is roughly consistent with the results of studies that have examined stock prices the day dividends are paid. For example, see Alan J. Auerbach, "Stockholder Tax Rates and Firm Attributes," unpublished, Harvard University, June 1981.

10. In any given year, measured capital gains are likely to differ from this figure because of recapitalizations due to information about future prospects of firms or changes in the discount rate. Because the aim here is to focus on the taxation of returns to investment, these recapitalizations are ignored. 
but excluded from this one, is over 100 percent due to the very low level of real interest rates. Second, there does not appear to have been a sizable increase in the taxation of equity income during the last decade. The statutory tax reductions in the form of accelerated depreciation, increases in the investment tax credit, and the recent reduction in the corporate tax rate have more than offset the positive impact of inflation on the taxation of corporate capital. These data do not contradict the assertion that the interaction between inflation and taxes has adversely affected capital formation. Rather, they indicate that these effects have worked either through a reduction in saving due to a reduced real after-tax interest rate or that they have been offset by changes in the tax laws. The historical data are not necessarily indicative of future developments. Even if the rate of inflation remains stable, with unchanged tax laws the effective tax rate on corporate capital will continue to rise because of historical cost depreciation.

The fact that effective tax rates did not rise during the 1970s does not by itself invalidate the case for tax reform. Appropriate tax policy depends on social objectives and the effects of reform, not consistency with historical norms. In the next part of the paper I develop a methodology for evaluating the effects of tax policies on capital formation and the distribution of wealth.

\section{Taxes in a $q$ Theory of Investment}

This section describes a procedure for using investment equations based on Tobin's $q$ as a basis for estimating the impact of tax policies on both investment and the stock market. The essential insight underlying Tobin's theory is that, in a taxless world, firms invest as long as each dollar spent purchasing capital raises the market value of the firm by more than one dollar. Tobin assumes that, to a good approximation, the market value of an additional unit of capital equals the average market value of the existing capital stock-that is, average $q$, which is the ratio of the market value of the capital stock to its replacement cost, is a good proxy for the value of the marginal $q$ on an additional dollar of investment. It is natural then to assume that the rate of investment is an increasing function of $q$. 
This approach has several advantages over more conventional theories of investment. Perhaps most important, the $q$ theory is supply-oriented. In the formulation below, firms make decisions on output and capital intensity simultaneously. This captures an important response to investment stimuli. Firms are encouraged to supply more output by a reduction in the cost of capital. This response is missing in most investment theories in which the level of output is taken as predetermined. ${ }^{11}$ As shown in appendix $\mathrm{A}$, the $q$ theory of investment can be derived by assuming that firms face adjustment costs and make investment and output decisions with the objective of maximizing market value.

A second advantage of $q$ theory is that it can be used readily to evaluate a wide menu of policy proposals. Almost all the empirical literature on tax policy and investment neglects entirely the taxes levied on individuals. These taxes are difficult to introduce into investment equations containing a flexible accelerator. Because they do have an impact on stock market values, individual income taxes are easily handled by the $q$-theory approach. In addition, because the $q$ theory is derivable directly from the assumption of intertemporal optimization, it is ideally suited for evaluation of the effects of policy announcements and comparing permanent and temporary policies. Similarly, the approach is forward-looking and so can be used to study the effects of future policies on current investment. As Robert Lucas has emphasized, econometric investment equations that do not incorporate rational adaptation to changes in policy cannot be used to predict the effects of those fundamental changes. ${ }^{12}$ The approach developed here is not subject to this criticism because the only parameters that are estimated are technological and do not depend on the policy

11. Peter K. Clark presents a review of these approaches and uses them to explain investment during the 1970s. See his "Investment in the 1970s: Theory, Performance, and Prediction," BPEA, 1:1979, pp. 73-113.

12. See Robert E. Lucas, Jr. "Econometric Price Evaluation: A Critique," in Karl Brunner and Allan H. Metzler, eds., The Phillips Curve and Labor Markets, Carnegie-Rochester Conference Series on Public Policy, vol. 1 (Amsterdam: NorthHolland, 1976), pp. 19-46. This criticism is appropriate at two levels. First, most approaches of the type used in policy evaluation exercises do not distinguish current and future values of variables. Thus there is no way to use them to investigate the effect of an announced change in policy. Implicitly, they assume that all tax parameters are expected to remain permanently constant. Second, because expected tax changes are an important feature of the historical experience, the equations are misspecified so that parameter estimates are unlikely to be reliable. The importance of these problems is demonstrated by the simulations below. 
rule; the theory shows how the implications of rational expectations of future events for optimal investment are appropriately captured in market values. ${ }^{13}$

The derivation of the $q$ theory of investment in this paper becomes more complex when financial and tax policies are modeled in full generality. It is useful to begin by considering a highly simplified model that highlights some of the main issues before introducing a realistic treatment of tax and financial policies.

\section{THE BASIC MODEL}

The dynamics of investment and market valuation are considered in a model in which there is no inflation, capital does not depreciate, investment is financed through retained earnings, and the only tax is a proportional levy on corporate income. In this setting it is reasonable to assume that investment depends on the ratio of the market value of existing capital to its replacement cost. Unless an investment of one dollar increases the market value of the firm by more than one dollar, there is no reason to invest. Given the costs of adjustments and lags in recognition and implementation, there is no reason to expect that all investments that increase market value by more than their cost will be made immediately. As Tobin has argued, these considerations lead to an investment equation of the form

$$
\begin{aligned}
I & =I\left(\frac{V}{K}\right) K \\
I(1) & =0 \quad I^{\prime}>0,
\end{aligned}
$$

where $I$ represents gross investment and $V / K$ is the $q$ ratio of market value to replacement cost. ${ }^{14}$ Since inflation is assumed to be zero, the price of capital can be taken to be 1 . The assumption that the ratio $I / K$ de-

13. Alternative approaches to investment exist that are also not subject to the Lucas critique. These involve the specification of fixed delivery lags for capital goods. For empirical application but not estimation using such approaches, see Robert E. Hall and Knut A. Mork, "Energy Prices and the U.S. Economy in 19791980," The Energy Journal, vol. 1 (April 1980), pp. 41-53; and Robert E. Hall, "The Macroeconomic Impact of Changes in Income Taxes in the Short and Medium Runs," Journal of Political Economy, vol. 86, pt. 2 (April 1978), pp. S71-S85.

14. James Tobin, "A General Equilibrium Approach To Monetary Theory," Journal of Money, Credit and Banking, vol. 1 (February 1969), pp. 15-29. 
pends on $q$ ensures that the growth rate of the capital stock is independent of the scale of the economy. It is important to recognize that the investment schedule given by equation 1 is a technological relation that depends on the adjustment cost function.

The analysis below is illustrative; adjustment costs are not explicitly recognized. An important assumption of this approach is that capital is homogeneous. If capital is heterogeneous, shocks may reduce the market value of existing capital but raise the return on new investment. Recent energy shocks illustrate this phenomenon. ${ }^{15}$

It is assumed that equity owners require a fixed real rate of return to induce them to hold the existing stock of equity. This return comes in the form of dividends-equal to after-tax profits minus retained earnings for new investment - and capital gains. Hence the condition,

$$
\rho=\frac{D i v}{V}+\frac{\dot{V}}{V}
$$

where $\rho$ is the real after-tax rate of return, Div is dividends, and $\dot{V}$ is $d V / d t$; and equation 2 implies ${ }^{16}$

$$
\dot{V}=\rho V-(1-\tau) F^{\prime}(K) K+I\left(\frac{V}{K}\right) K,
$$

where $\tau$ is the corporate tax rate, and the production function, with labor input fixed, is given by $F(K)$. Because it is assumed that the economy's fixed labor stock is fully employed, the rate of profit, $F^{\prime}(K)$, declines as the capital stock increases. It will be convenient to examine the dynamics in terms of $K$ and $q$. Equations 1 and 3 imply that the system's equations of motion are

$$
\begin{gathered}
\dot{K}=I(q) K \\
\dot{q}=[\rho-I(q)] q+I(q)-(1-\tau) F^{\prime}(K) .
\end{gathered}
$$

The steady-state properties of the model are easily found by imposing

15. Martin Baily's paper in this issue argues for the importance of such effects. However, empirical efforts to verify a divergence between marginal and average $q$ have not been successful. See John P. Shoven and Arthur B. Slepian, "The Effects of Factor Price Changes on Replacement Investment and Market Valuation," Discussion Paper 19 (Workshop on the Microeconomics of Inflation, Stanford University, October 1978).

16. Here and throughout the paper a dot above a variable denotes the derivative of that variable with respect to time. 
Figure 1. Dynamics of Investment and Market Valuation

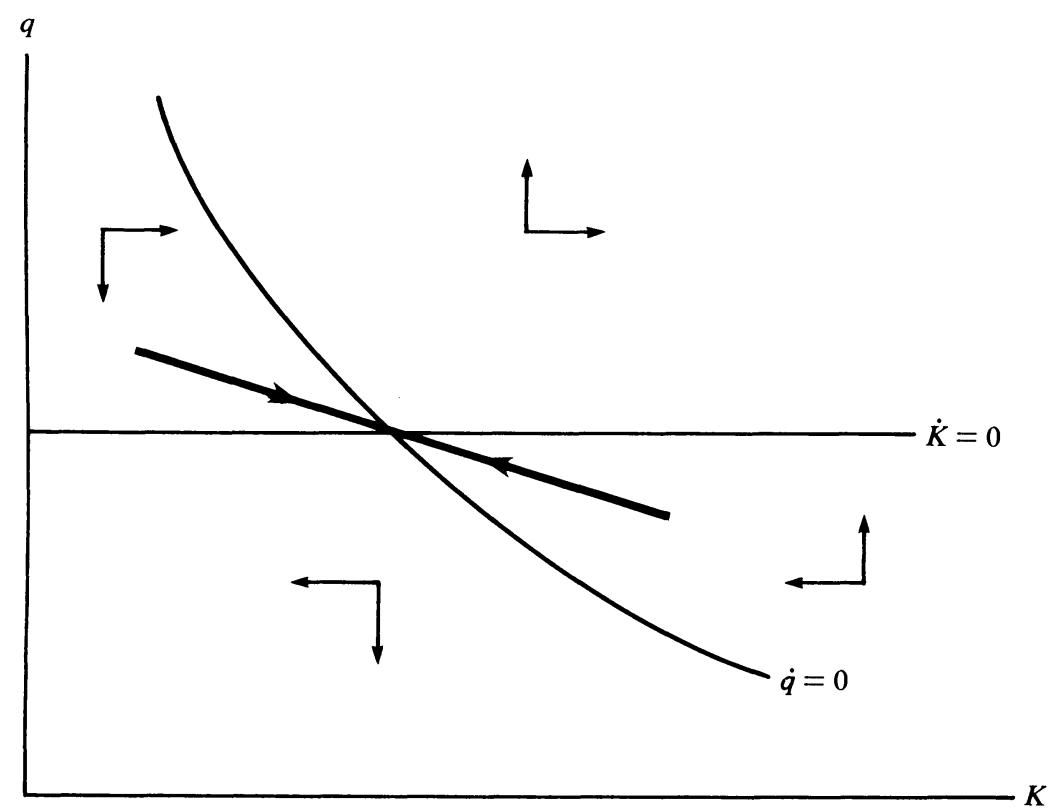

the conditions $\dot{K}=0$ and $\dot{q}=0$. These imply

$$
\begin{gathered}
q=I^{-1}(0)=1 \\
\rho=(1-\tau) F^{\prime}(K) .
\end{gathered}
$$

Equation 6 indicates that in the steady state the value of $q$ must equal 1 so that the market value of capital goods equals their replacement cost. Equation 7 indicates that, in equilibrium, firms equate their net marginal product of capital with the cost of capital. Inspection of equations 6 and 7 makes clear that a change in the corporate tax rate affects the steady-state capital stock but has no effect on steady-state $q$ because the change does not influence the cost to the firm of acquiring new capital goods.

The dynamics of adjustment following a tax change are illustrated in figure 1, a phase diagram representing equations 4 and $5 .{ }^{17}$ In the figure, the arrows depict the equations of motion of the system when it is not in

17. Note that the figure is drawn to correspond to the empirically relevant case in which dividends are positive. For sufficiently large $q$, the $\dot{q}=0$ schedule would be negatively sloped. 
Figure 2. Response to a Corporate Tax Cut

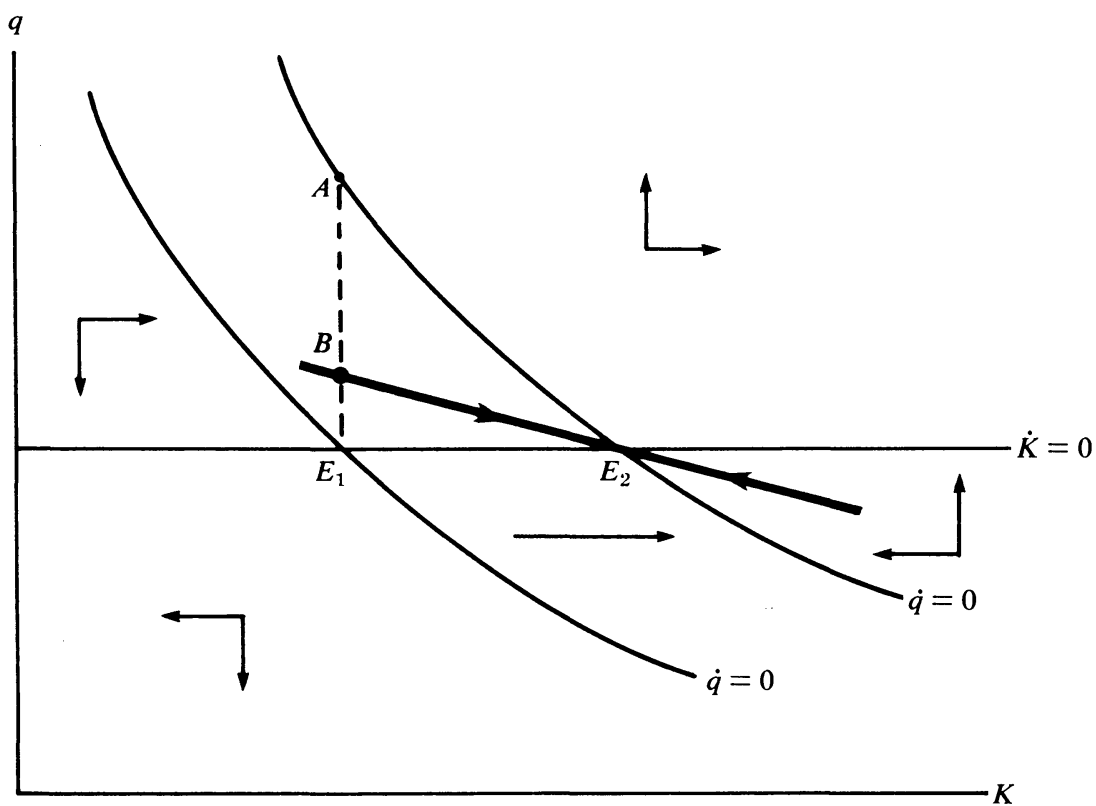

equilibrium. The dark line represents the saddle-point path along which the system will converge to a steady state. ${ }^{18} \mathrm{~A}$ reduction in the corporate tax rate does not immediately affect the capital stock. The value of $q$ jumps from $E_{1}$ to $B$, as shown in figure 2. As capital is accumulated, the marginal product of capital falls and the system converges to $E_{2}$, where $q$ is again equal to its equilibrium value. This path assumes that investors have perfect foresight and take account of the capital losses that occur as capital is accumulated. An alternative assumption is that the investors have myopic expectations and fail to foresee the effects of capital accumulation. In this case, the system jumps from $E_{1}$ to $A$ and then converges to $E_{2}$ along the $\dot{q}=0$ schedule; along this transition path investors consistently earn less than their required rate of return.

18. The knife-edge stability of the saddle-point path is a common feature of models with asset prices. Andrew B. Abel was the first to use an approach of this type to analyze investment incentives. See his "Empirical Investment Equations: An Integrative Framework," in Karl Brunner and Allan H. Metzler, eds., On the State of Macro-Economics, Carnegie-Rochester Conference Series on Public Policy, vol. 12 (Amsterdam: North-Holland, 1980), pp. 39-91. 
Equations 4 and 5 can be solved numerically to find the path of $q$ and the capital stock that would follow any shift in $q$, independent of its source. Shocks that might affect $q$ include announcements of future tax policy changes as well as temporary or permanent policy measures. All that is necessary is knowledge of the form of the production function and the $q$ investment relation. However, realistic estimates require taking account of the complexities of the tax code, corporate financial policy, and the consequences of inflation. The nature of the modifications required by these factors is discussed heuristically below.

\section{ADDING TAX EFFECTS}

The formulation above abstracts from a number of important aspects of reality, including debt finance, personal taxes, and depreciation. In this section, I show how to construct a tax-adjusted $q$, hereafter denoted $Q$, which can be used in a correctly specified investment equation. (A formal derivation of $Q$ is provided in appendix $\mathrm{A}$.) I begin by introducing debt finance. It is assumed that firms finance a fraction, $b$, of new investment by issuing debt. Hence they continue to invest as long as the increase in equity value from a new investment exceeds its cost, $1-b$, to equity holders. Recognition of debt therefore leads to a simple modification of the investment equation:

$$
\begin{gathered}
\frac{I}{\bar{K}}=h\left(\frac{V}{p K}+b-1\right)=h(Q) \\
h(0)=0 \quad h^{\prime}>0,
\end{gathered}
$$

where $p K$ is the nominal value of the capital stock. The expression $(V / p K)+b$ is Tobin's $q$ variable as normally defined.

The next step is to introduce a tax or subsidy on the effective purchase price of new capital goods. The investment tax credit directly reduces the real acquisition cost of new capital goods; the knowledge that the purchase of a new capital good carries with it a stream of future tax-deductible depreciation allowances has a similar effect. These two factors reduce the effective price of capital goods from $(1-b)$ to $(1-b-I T C-Z)$, where ITC is the investment tax credit and $Z$ is the present value of the tax savings from the depreciation deductions arising on a new investment of one dollar. This cost must be compared with the increase in the market value that results from the purchase. Under the assumption stated above 
- that capital is homogeneous - the increase in the stock market value of a firm brought about by an extra dollar of investment is $(V-B) / p K$, where $B$ is the present value of the tax savings due to depreciation deductions on existing capital. These must be subtracted because they are not related to new capital; $Z$ already takes account of the depreciation allowances expected on new capital. These adjustments lead to the investment equation,

$$
\begin{gathered}
\frac{I}{K}=h\left(\frac{V-B}{p K}-1+b+I T C+Z\right)=h(Q) \\
h(0)=0 \quad h^{\prime}>0 .
\end{gathered}
$$

Next it is necessary to take account of taxes levied on the individual for dividends and capital gains. At the margin, the firm is faced with a choice between retaining and investing a dollar or paying it out as dividends. Because the rate of dividend taxation exceeds the rate of capital gains taxation, firms invest past the point at which a dollar of retained earnings raises market value by one dollar. In particular, they will retain earnings until this last dollar raises market value by $(1-\theta) /(1-c)$ dollars. This implies that equation 9 should be modified to

$$
\begin{gathered}
\frac{I}{K}=h\left(\frac{(V-B)(1-c)}{p K(1-\theta)}-1+b+I T C+Z\right)=h(Q) \\
h(0)=0 \quad h^{\prime}>0,
\end{gathered}
$$

where $\theta$ and $c$ are the marginal tax rate on dividends and the effective capital gains rate, respectively.

The final modification is to recognize that adjustment costs are expensed. This implies that firms invest until the market value of the additional capital minus its acquisition cost equals the after-tax cost of installation. When the corporate tax rate rises, marginal installation costs decline on an after-tax basis so investment increases, other things being equal. This consideration leads to the final expression for $Q$ :

$$
\begin{gathered}
\frac{I}{K}=h\left(\frac{\frac{(V-B)(1-c)}{p K(1-\theta)}-1+b+I T C+Z}{(1-\tau)}\right)=h(Q) \\
h(0)=0 \quad h^{\prime}>0 .
\end{gathered}
$$

A more formal statement of this expression is presented in appendix A. 
Figure 3. Increase in the Investment Tax Credit

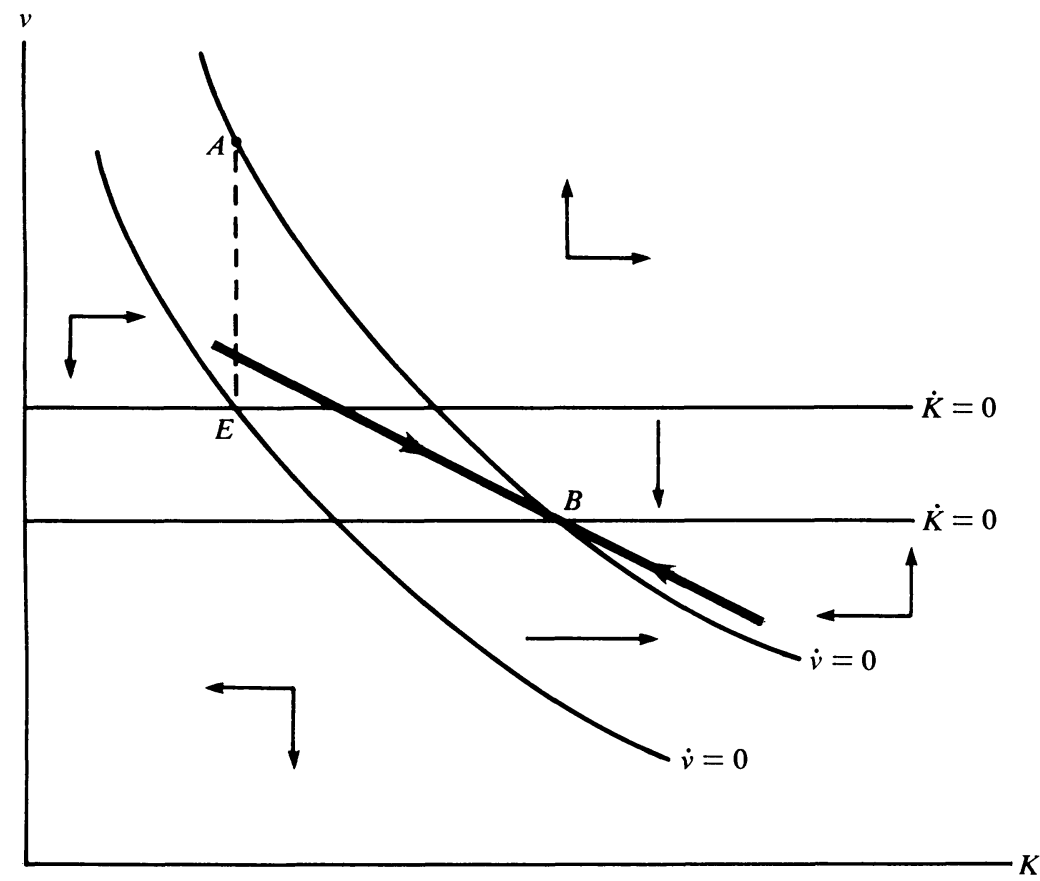

Equation 11 characterizes the motion of the capital stock. In order to analyze this model it is also necessary to describe the evolution of $V / p K$, denoted by $v{ }^{19}$ It is not difficult to show that it evolves according to the equation,

$$
\dot{v}=\frac{\rho+\pi}{(1-c)} v-\frac{(1-\theta)}{(1-c)} \frac{D i v}{p K}-v\left(\pi+\frac{\dot{K}}{K}\right)
$$

where $\pi$ is the rate of inflation.

Figure 3 shows a phase diagram for equations 11 and 12 for given tax parameters. As in figure 1, the equations and diagram can be interpreted as referring to the entire economy rather than an individual firm. Qualitatively the diagram looks like the one shown in figure 1 . However, if the economy is growing it is necessary to interpret $K$ as the ratio of capital to labor. The diagram also exhibits saddle-point stability. Again there is a

19. This expression follows immediately from the definition of $v$ and equation A-1 in appendix A. 
Figure 4. Increase in the Corporate Income Tax

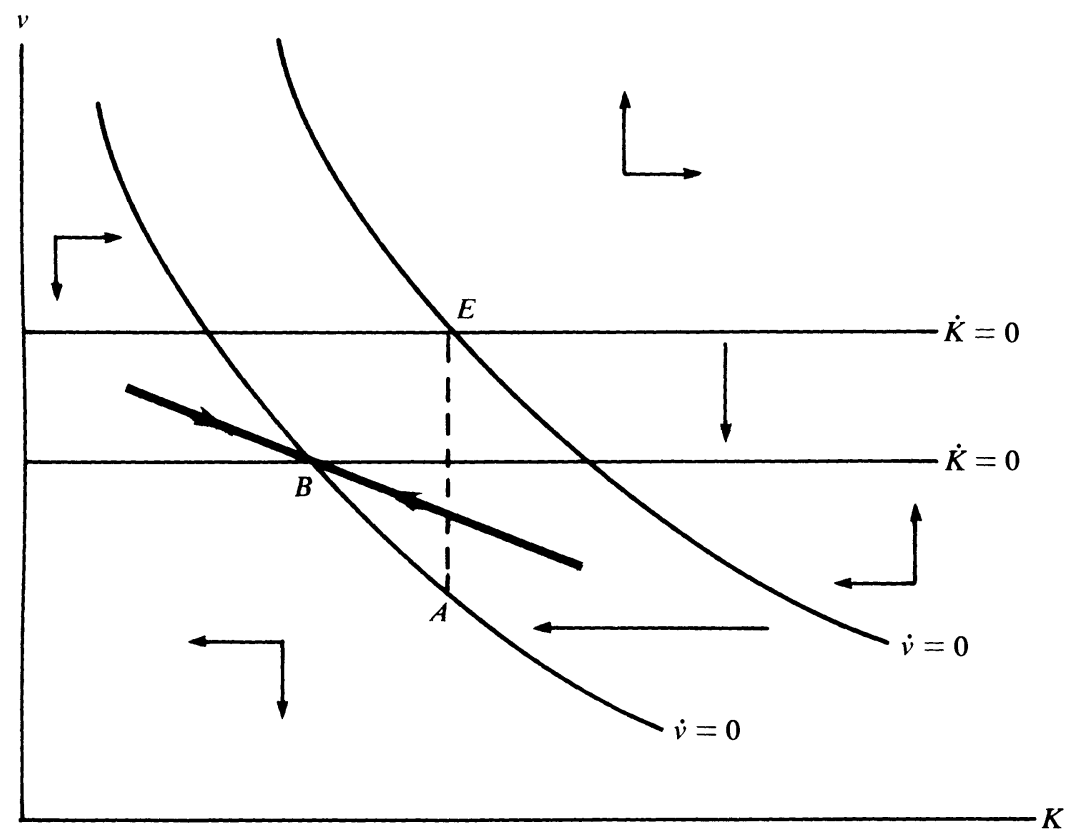

unique path, indicated by the dark line, along which the system converges to equilibrium. On this path, which assumes perfect foresight, investment is just sufficient to validate the market's expectations about future dividends. This phase diagram can be used to study the relations among tax changes, market valuation, and investment.

Consider an increase in the investment tax credit as shown in figure 3. Both schedules shift: the $\dot{K}=0$ schedule shifts downward because the investment tax credit reduces the effective purchase price of new capital goods, and the $\dot{v}=0$ schedule shifts to the right because the investment tax credit raises after-tax profits. The diagram shows that the steady-state capital stock unambiguously increases. In the long run the value of $v$ falls because the credit reduces the "effective" replacement cost of capital goods. The short-run impact on stock market valuation is ambiguous, depending on the rapidity of adjustment. It is possible for $v$ to jump to any level between $A$, which corresponds to no capital stock adjustment, and $B$, which corresponds to an instantaneous adjustment of the capital stock. It is thus possible that the stock market may decline even though 
Figure 5. Announcement Effect: Dividend Tax Increase

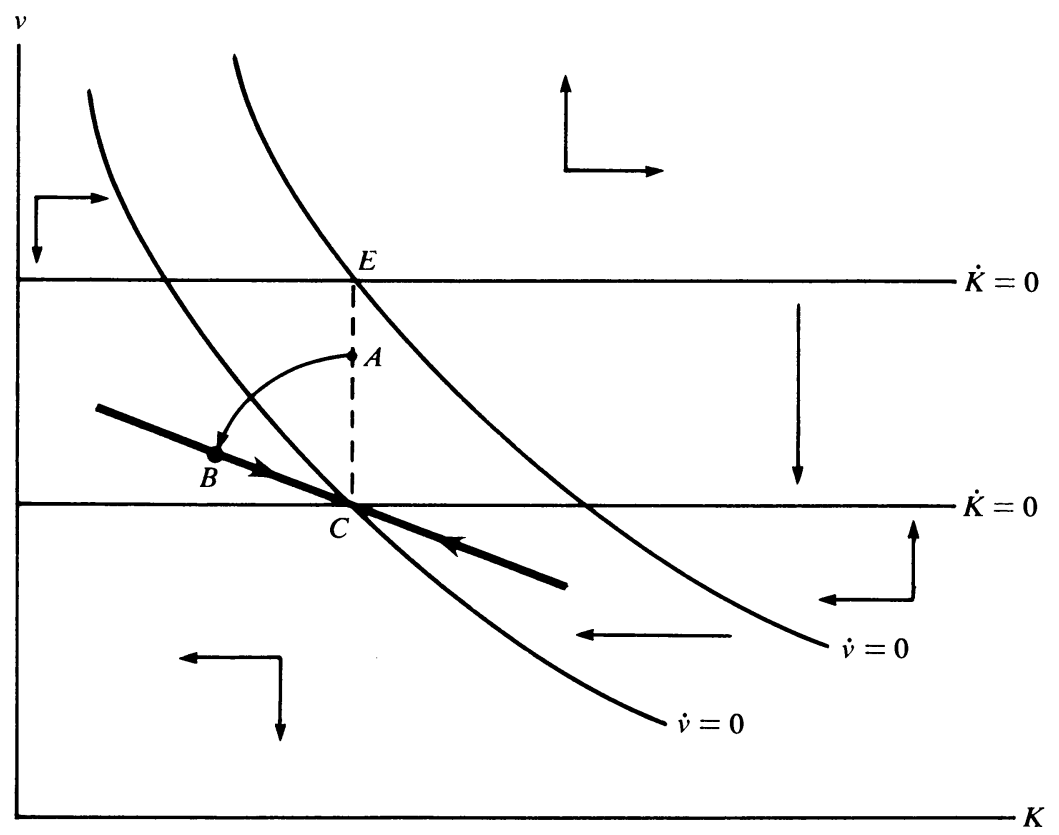

investment has been encouraged. Exactly parallel results hold for a decline in the capital gains tax rate or for an acceleration of tax depreciation.

An increase in the corporate tax rate, as shown in figure 4 , has an ambiguous effect on long-run capital accumulation. The $\dot{v}=0$ schedule is likely to shift to the left, reflecting the effect of increased taxes in reducing dividends and the $\dot{K}=0$ schedule will shift downward because of the expensing of adjustment costs and the increased value of the tax deduction for depreciation. Hence the value of the market will unambiguously decline in the short run, but the short-run impact on investment and the long-run effects on the capital stock are indeterminate.

One advantage of the investment theory developed here is that it can easily be used to analyze the effects of both temporary and announced, but not yet implemented, tax changes. Figure 5 illustrates the effects of an announcement that, at some point in the future, the dividend tax rate will be increased. There is no immediate effect on either schedule. At time $t$, when the tax increase takes effect, both schedules shift downward as shown. With the assumptions already made, a change in the dividend tax 
has no impact on long-run capital intensity. But the change does alter the timing of investment decisions. Firms have an incentive to pay extra dividends before the increase in the dividend tax takes effect and to pay lower subsequent dividends. Following the announcement, the stock market declines to point $A$; as firms raise dividends and reduce investment, the system moves to $B$. At time $t$, when the dividend tax is increased, the economy moves along the stable path from $B$ to the new equilibrium $C$. Note that the announcement of the tax reduces investment but that investment actually rises sharply at the moment the change goes into effect.

These examples illustrate cases in which tax changes can have opposite effects on the stock market and investment and demonstrate the importance of taking tax factors into account in estimating relations between market valuation and investment. The next section describes the estimation of investment equations based on $q$ theory.

\section{Estimating the Relation between Investment and $Q$}

In order to use the theoretical framework outlined above to examine the response of investment to changes in tax policy, it is first necessary to estimate the relation between investment and $Q$. This relation can be interpreted as tracing the economy's adjustment-cost schedule for installing new investments. As the value of $Q$ rises, firms increase their investment until they are just indifferent between installing an extra unit of capital and paying out its cost in the form of higher dividends. For simplicity it is assumed that adjustment is costless until some normal level of investment is reached, and then marginal adjustment costs rise linearly with investment. As shown in appendix A, this implies a linear relation between the ratio of investment to capital stock and $Q$. The estimated empirical relation between investment and $q$ can be solved to find the parameters of the underlying adjustment-cost function.

The basic equations estimated in this section are of the form

$$
\frac{I}{K}=\gamma+\frac{1}{\beta} Q+u \text {. }
$$

In the explanation of investment an effort is made to contrast the performance of $Q$ with a conventional measure, $q$, which is not adjusted for taxes. Although several authors have estimated variants of equation 13, 
none has taken full account of the tax effects outlined here ${ }^{20}$ Typically these studies have related components of total business fixed investment to $q$, a procedure that may not be appropriate for noncorporate investment. The studies have also been confined to the period after the Korean War during which tax changes have been relatively minor.

To focus on tax effects, I examine the determinants of nonfinancial corporate investment over the entire 1931-78 period. The extension of the sample period introduces substantial variation in tax parameters. The dividend tax rate varied between 0.15 and 0.58 during the period; and the corporate rate between 0.18 and 0.70 . Extending the equation back this far necessitates some crudeness in the calculation of $Q$ and requires the use of annual data. Because the emphasis here is on long-run issues, this is probably not a serious problem. The calculation of the various components of $Q$ in equation 11 are described in appendix B.

Estimated values of $Q$ are displayed in table 3, together with estimates of conventional $q$ and measures of important tax effects. A striking feature of the table is the pronounced drop in $q$ during the past fifty years. ${ }^{21}$ The value of $q$ actually peaked in 1937. The tax factors shown in columns 3 and 5 may account for much of this long-term decline. The discount on the price of acquiring new capital goods that results from taxation has risen from about 10 percent in the 1930 s to close to 40 percent in the 1970s, as shown in column 3 . This effect exceeds the offsetting increases in the value of future depreciation allowances on existing capital shown in column 4. An additional factor that reduced $q$ relative to $Q$ over this long period is the increase in the tax cost to individuals of paying out dividends rather than retaining earnings, which is reflected in column 5 .

Taxes may also explain why $q$ is lower than theory predicts. Despite the fact that many assets of firms are intangible and are therefore excluded from the denominator of the $q$ ratio, it appears that $q$ averages less than its theoretical equilibrium value of unity. And in recent years,

20. Notable studies include George M. von Furstenberg, "Corporate Investment: Does Market Valuation Matter in the Aggregate?" BPEA, 2:1977, pp. 347-97; John H. Ciccolo, Jr., "Four Essays on Monetary Policy" (Ph.D. dissertation, Yale University, 1975); and Robert F. Engle and Duncan K. Foley, "An Asset Price Model of Aggregate Investment," International Economic Review, vol. 16 (October 1975), pp. 625-47.

21. Another striking feature of the table is the great volatility of $Q$ relative to $q$. This is not because of variations in the tax parameters but arises because $V$ in equation 11 is divided by $(1-\tau)$ and multiplied by $(1-c) /(1-\theta)$. 
Table 3. Tax-Adjusted and Unadjusted Measures of $q, 1931-7^{\mathrm{a}}$

Ratio

\begin{tabular}{|c|c|c|c|c|c|}
\hline Year & $\stackrel{q}{q}$ & $\begin{array}{c}Q \\
(2)\end{array}$ & $\begin{array}{c}I T C+Z \\
\text { (3) }\end{array}$ & $\begin{array}{c}B / p K \\
(4)\end{array}$ & $\begin{array}{c}(1-\theta) /(1-c) \\
(5)\end{array}$ \\
\hline 1931 & 1.541 & 0.153 & 0.077 & 0.054 & 0.902 \\
\hline 1932 & 0.942 & -0.192 & 0.085 & 0.061 & 0.794 \\
\hline 1933 & 0.881 & -0.387 & 0.089 & 0.072 & 0.789 \\
\hline 1934 & 1.300 & 0.025 & 0.093 & 0.075 & 0.780 \\
\hline 1935 & 1.454 & 0.110 & 0.096 & 0.076 & 0.772 \\
\hline 1936 & 1.833 & 0.547 & 0.124 & 0.078 & 0.772 \\
\hline 1937 & 2.039 & 1.017 & 0.127 & 0.096 & 0.782 \\
\hline 1938 & 1.514 & 0.362 & 0.138 & 0.093 & 0.819 \\
\hline 1939 & 1.303 & 0.657 & 0.140 & 0.104 & 0.806 \\
\hline 1940 & 1.369 & 0.721 & 0.292 & 0.108 & 0.781 \\
\hline 1941 & 1.087 & 1.081 & 0.513 & 0.216 & 0.721 \\
\hline 1942 & 0.878 & 0.431 & 0.525 & 0.356 & 0.650 \\
\hline 1943 & 0.999 & 0.535 & 0.546 & 0.349 & 0.640 \\
\hline 1944 & 1.183 & 1.748 & 0.569 & 0.356 & 0.536 \\
\hline 1945 & 1.195 & 1.225 & 0.528 & 0.374 & 0.576 \\
\hline 1946 & 1.201 & 1.422 & 0.294 & 0.338 & 0.581 \\
\hline 1947 & 0.997 & 0.768 & 0.291 & 0.159 & 0.567 \\
\hline 1948 & 0.803 & 0.433 & 0.286 & 0.151 & 0.598 \\
\hline 1949 & 0.727 & 0.164 & 0.290 & 0.151 & 0.615 \\
\hline 1950 & 0.680 & 0.021 & 0.462 & 0.164 & 0.587 \\
\hline 1951 & 0.667 & 0.287 & 0.505 & 0.262 & 0.588 \\
\hline 1952 & 0.664 & -0.093 & 0.479 & 0.282 & 0.624 \\
\hline 1953 & 0.666 & 0.044 & 0.465 & 0.272 & 0.589 \\
\hline 1954 & 0.725 & -0.090 & 0.409 & 0.277 & 0.599 \\
\hline 1955 & 0.850 & 0.485 & 0.415 & 0.240 & 0.583 \\
\hline 1956 & 0.894 & 0.899 & 0.415 & 0.239 & 0.585 \\
\hline 1957 & 0.854 & 0.703 & 0.405 & 0.227 & 0.593 \\
\hline 1958 & 0.870 & 0.389 & 0.410 & 0.220 & 0.583 \\
\hline 1959 & 0.995 & 0.976 & 0.398 & 0.226 & 0.594 \\
\hline 1960 & 1.075 & 1.349 & 0.399 & 0.220 & 0.601 \\
\hline 1961 & 1.156 & 1.192 & 0.402 & 0.223 & 0.592 \\
\hline 1962 & 1.199 & 1.931 & 0.427 & 0.229 & 0.599 \\
\hline 1963 & 1.240 & 1.309 & 0.438 & 0.235 & 0.597 \\
\hline 1964 & 1.350 & 1.853 & 0.424 & 0.237 & 0.632 \\
\hline 1965 & 1.413 & 2.008 & 0.413 & 0.224 & 0.646 \\
\hline 1966 & 1.323 & 2.415 & 0.395 & 0.211 & 0.640 \\
\hline 1967 & 1.234 & 1.317 & 0.389 & 0.199 & 0.630 \\
\hline 1968 & 1.240 & 1.942 & 0.422 & 0.189 & 0.586 \\
\hline 1969 & 1.178 & 2.257 & 0.377 & 0.195 & 0.601 \\
\hline
\end{tabular}


Table 3 (continued)

\begin{tabular}{cccccc}
\hline Year & $q$ & $Q$ & $I T C+Z$ & $B / p K$ & $(1-\theta) /(1-c)$ \\
$(1)$ & $(2)$ & $(3)$ & $(4)$ & $(5)$ \\
\hline 1970 & 1.002 & 1.195 & 0.330 & 0.182 & 0.628 \\
1971 & 0.959 & 0.842 & 0.360 & 0.156 & 0.631 \\
1972 & 1.055 & 0.851 & 0.375 & 0.155 & 0.634 \\
1973 & 1.029 & 1.390 & 0.374 & 0.156 & 0.634 \\
1974 & 0.815 & 0.781 & 0.359 & 0.145 & 0.649 \\
1975 & 0.697 & -0.135 & 0.371 & 0.125 & 0.619 \\
1976 & 0.743 & 0.342 & 0.376 & 0.120 & 0.606 \\
1977 & 0.747 & 0.641 & 0.381 & 0.119 & 0.606 \\
1978 & 0.671 & 0.216 & 0.372 & 0.120 & 0.606 \\
\hline
\end{tabular}

Source: Calculations by the author.

a. Variables are described in the text.

although $q$ has remained well below unity, not only gross but also net investment has been positive. Contrary to the predictions of the theory, the $Q$ variable is greater than its zero investment threshold in almost every year. ${ }^{22}$ It does not show any tendency to remain below its equilibrium value.

The tax-adjustment terms in columns 3 through 5 are of interest in their own right. Column 3 shows that the effect of inflation and the associated rise in nominal interest rates has been a slight rise in the after-tax price of new capital goods during the 1970s. The rise would have been larger without the increases in the investment tax credit and the generosity of depreciation allowances that have been legislated.

Column 4 reveals that the entitlement to future depreciation allowances on the existing capital stock is an important asset of the nonfinancial corporate sector. At the end of 1978, the value of the "depreciation bond" was $\$ 190$ billion, which represented more than a quarter of the market value of equity. The combination of accelerating depreciation allowances, inflation, and a reduction in statutory corporate rates has led to a large decline in the value of this asset from over 20 percent of the capital stock in the mid-1960s. It is reasonable to speculate that the decline in $B$ has contributed to the recent sharp fall in $q$. Evidence bearing on this conjecture is presented in the simulations below.

Finally, column 5 examines the evolution of the effects of taxes on individuals. After declining between the 1930s and 1940s, these effects

22. Note that in a taxless world, $Q=q-1$. 
Table 4. $q$ Investment Equations, 1932-78 ${ }^{\mathrm{a}}$

\begin{tabular}{|c|c|c|c|c|c|c|}
\hline \multirow[b]{2}{*}{ Equation $^{\mathrm{b}}$} & \multirow[b]{2}{*}{ Constant } & \multicolumn{2}{|c|}{ Independent variable } & \multicolumn{3}{|c|}{ Summary statistic } \\
\hline & & $q-1$ & $Q$ & Rho & $\begin{array}{l}\text { Standard } \\
\text { error of } \\
\text { estimate }\end{array}$ & $\begin{array}{l}\text { Durbin- } \\
\text { Watson }\end{array}$ \\
\hline $4-1$ & $\begin{array}{c}0.119 \\
(0.006)\end{array}$ & $\begin{array}{c}-0.038 \\
(0.019)\end{array}$ & $\ldots$ & $\cdots$ & 0.039 & 0.29 \\
\hline $4-2$ & $\begin{array}{c}0.096 \\
(0.008)\end{array}$ & $\cdots$ & $\begin{array}{c}0.026 \\
(0.007)\end{array}$ & $\ldots$ & 0.036 & 0.21 \\
\hline $4-3$ & $\begin{array}{c}0.104 \\
(0.035)\end{array}$ & $\begin{array}{c}0.039 \\
(0.016)\end{array}$ & $\ldots$ & 0.944 & 0.017 & 1.27 \\
\hline $4-4$ & $\begin{array}{c}0.096 \\
(0.025)\end{array}$ & $\cdots$ & $\begin{array}{c}0.017 \\
(0.004)\end{array}$ & 0.923 & 0.016 & 1.12 \\
\hline $4-5$ & $\begin{array}{c}0.084 \\
(0.033)\end{array}$ & $\begin{array}{c}0.013 \\
(0.018)\end{array}$ & $\begin{array}{c}0.015 \\
(0.005)\end{array}$ & 0.933 & 0.016 & 1.11 \\
\hline $4-6$ & $\begin{array}{c}0.088 \\
(0.024)\end{array}$ & $\cdots$ & $\begin{array}{c}0.031 \\
(0.005)\end{array}$ & 0.922 & 0.016 & 1.11 \\
\hline $4-7$ & $\begin{array}{c}0.230 \\
(0.039)\end{array}$ & $\begin{array}{r}-0.106 \\
(0.036)\end{array}$ & $\cdots$ & $\cdots$ & 0.044 & 0.43 \\
\hline $4-8$ & $\begin{array}{c}0.076 \\
(0.012)\end{array}$ & $\cdots$ & $\begin{array}{c}0.051 \\
(0.013)\end{array}$ & $\ldots$ & 0.040 & 0.34 \\
\hline
\end{tabular}

Source: Estimations by the author.

a. The dependent variable is $I / K$. Equations in which rho is omitted were estimated without autocorrelation correction. The numbers in parentheses are standard errors.

b. For equation 4-6, the coefficient on $Q$ is the sum of the coefficient on $Q$ and lagged $Q$. Equations 4-7 and 4-8 were estimated using as instruments the lagged values of the tax variables, $\theta, c, r, Z$, and ITC.

have not changed greatly for many years-the cost of paying out dividends has been fairly constant since World War II. But current policy proposals for drastic reductions in the tax rates for individuals in top brackets could reduce the incentive of firms to retain earnings.

Tables 4 and 5 present estimates of the simple investment functions given in equation 13 , using $Q$ and $q$ as alternative explanatory variables. Before examining the results, it is necessary to comment on the estimation. First, the primary goal of this empirical work is to compare the performance of $Q$ with that of the conventional $q$ variable and to estimate parameters of the adjustment-cost function. The equations are not intended to provide the best possible explanation of actual investment behavior during the sample period. The fit of these equations could undoubtedly be improved by including other variables to pick up short-run influences on investment, but this approach is not pursued here because 
Table 5. Postwar $Q$ Investment Equations, 1948-78 ${ }^{\text {a }}$

\begin{tabular}{|c|c|c|c|c|c|c|}
\hline \multirow[b]{2}{*}{ Equation $^{\mathrm{b}}$} & \multirow[b]{2}{*}{ Constant } & \multicolumn{2}{|c|}{ Independent variable } & \multicolumn{3}{|c|}{ Summary statistic } \\
\hline & & $q-1$ & $Q$ & Rho & $\begin{array}{c}\text { Standard } \\
\text { error of } \\
\text { estimate }\end{array}$ & $\begin{array}{l}\text { Durbin- } \\
\text { Watson }\end{array}$ \\
\hline $5-1$ & $\begin{array}{c}0.138 \\
(0.002)\end{array}$ & $\begin{array}{c}0.025 \\
(0.009)\end{array}$ & $\cdots$ & $\cdots$ & 0.012 & 0.92 \\
\hline $5-2$ & $\begin{array}{c}0.128 \\
(0.003)\end{array}$ & $\cdots$ & $\begin{array}{c}0.009 \\
(0.003)\end{array}$ & $\cdots$ & 0.011 & 0.73 \\
\hline $5-3$ & $\begin{array}{c}0.140 \\
(0.004)\end{array}$ & $\begin{array}{c}0.034 \\
(0.019)\end{array}$ & $\cdots$ & 0.582 & 0.011 & 1.88 \\
\hline $5-4$ & $\begin{array}{c}0.127 \\
(0.007)\end{array}$ & $\cdots$ & $\begin{array}{c}0.015 \\
(0.004)\end{array}$ & 0.763 & 0.009 & 1.97 \\
\hline $5-5$ & $\begin{array}{c}0.135 \\
(0.021)\end{array}$ & $\begin{array}{r}-0.010 \\
(0.026)\end{array}$ & $\begin{array}{c}0.016 \\
(0.004)\end{array}$ & 0.721 & 0.009 & 1.94 \\
\hline $5-6$ & $\begin{array}{c}0.123 \\
(0.012)\end{array}$ & $\cdots$ & $\begin{array}{c}0.025 \\
(0.005)\end{array}$ & 0.894 & 0.008 & 1.93 \\
\hline $5-7$ & $\begin{array}{c}0.098 \\
(0.014)\end{array}$ & $\begin{array}{c}0.042 \\
(0.015)\end{array}$ & $\cdots$ & $\cdots$ & 0.012 & 0.77 \\
\hline $5-8$ & $\begin{array}{c}0.124 \\
(0.004)\end{array}$ & $\cdots$ & $\begin{array}{c}0.015 \\
(0.005)\end{array}$ & $\cdots$ & 0.011 & 0.58 \\
\hline
\end{tabular}

Source: Estimations by the author.

a. The dependent variable is $I / K$. Equations in which rho is omitted were estimated without autocorrelation correction. The numbers in parentheses are standard errors.

b. For equation 5-6, the coefficient on $Q$ is the sum of the coefficient on $Q$ and lagged $Q$. Equations 5-7 and 5-8 were estimated using as instruments the lagged values of the tax variables, $\theta, c, \tau, Z$, and ITC.

of the focus on long-run issues. ${ }^{23}$ Second, the appropriate econometric procedures are not clearcut in this context, as Engle and Foley emphasize; theory suggests that most of the power in the relation between investment and $q$ should be found at low frequencies. ${ }^{24}$ Transforming the data to correct for autocorrelation places greater weight on high frequencies and therefore may be inappropriate. ${ }^{25}$ This point takes on increased importance in light of the extreme volatility of the stock market and evidence

23. If other variables were added to the equation, the coefficient on $Q$ could no longer be interpreted as a measure of marginal adjustment costs.

24. Engle and Foley, "Asset Price Model."

25. Robert J. Shiller, "Do Stock Prices Move Too Much To Be Justified by Subsequent Changes in Dividends?" Working Paper 456 (National Bureau of Economic Research, February 1980). 
that there is substantial "noise" in share price movements. ${ }^{26}$ Third, there are reasons to doubt the exogeneity of the $q$ variables. ${ }^{27}$ For instance, shocks to the adjustment technology may induce spurious correlation between $q$ and investment. These problems are examined by estimating equation 13 using instrumental variables in some of the specifications. Finally, while not strictly justified by the theory, lagged values of $Q$ are included in the investment equations to take account of delivery lags and difficulties in the alignment of the investment and $Q$ series.

The results in table 4 provide evidence that the inclusion of tax effects contributes to the explanatory power of the $Q$ theory. Regardless of the treatment of autocorrelation, $Q$ has more explanatory power gauged in terms of its own statistical significance or regression standard errors than does $q$. When both variables are entered in the same equation, $Q$ is highly significant and the coefficient on $q$ is smaller than its standard error. Reestimating the equations using instrumental variables provides strong support for the importance of tax effects- $Q$ is highly significant while $q$ has the wrong sign.

Similar results emerge in table 5. The $Q$ variable continues to outperform $q$, even though the tax effects vary much less during the postwar period. In all cases, the hypothesis that the relation is stable between the two parts of the sample cannot be rejected. A variety of other statistical tests were performed in an effort to examine the robustness of the results. Allowing for second-order serial correlation, deleting the World War II and Korean War periods, and varying the instruments used had no important effect on the results. The results are also insensitive to the inclusion of more lags or a time trend.

Changes in tax policy operate both by changing $V$ and through the tax adjustment contained in equation 11 . It should be stressed that the superior performance of $Q$ in explaining investment, which suggests the importance of tax effects, does not test the importance of the tax effects that work through $V$. The results obtained here only indicate the importance of the latter effects. Equation 4-6, for example, implies that an increase

26. This point is amplified in Christopher A. Sims, "The Role of Approximate Prior Restrictions in Distributed Lag Estimations," Journal of the American Statistical Association, vol. 67 (March 1972), pp. 169-75. It is a variant of the common observation that autocorrelation corrections exacerbate the errors in variables problems.

27. This point is developed in Thomas J. Sargent, “'Tobin's $q$ ' and the Rate of Investment in General Equilibrium," in Brunner and Metzler, eds., On the State of Macro-Economics, pp. 107-54. 
of 5 percentage points in the investment tax credit would raise total investment by about 3 percent even if it had no impact on market value. As shown below, the effect would be much greater if changes in market value were added.

The parameter estimates obtained are consistent with earlier studies. Equation 4-6 suggests that $d(I / K) / d Q$ approximately equals 0.031 ; and equation 13 implies $d Q / d(V / p K)$ approximately equals 3 . The implied estimate that a 10 percent increase in the value of the stock market raises $I / K$ by about 0.009 is very similar to the estimates found in previous studies. $^{28}$

\section{ESTIMATING THE IMPACTS OF TAX POLICY}

The theoretical framework outlined above, together with the regression results, provides a basis for estimating the impacts of tax reforms on investment. In order to do this, it is necessary to provide numerical estimates of the key parameters relating to the production function, financial decisions, and taxes.

Technological Assumptions. It is assumed that production of gross output in the nonfinancial corporate sector is given by a Cobb-Douglas production function. The assumption is quite common in the literature on investment and is consistent with the constancy of factor shares despite the changing ratio of capital to output. The share of capital in the production function is taken to be 0.25 . This is quite close to the observed value in the nonfinancial corporate sector. Effective labor supply, which is taken to be exogenously determined, is assumed to grow at 3 percent a year. Because of the focus on long-run issues, full employment is assumed.

The level of investment is assumed to be determined by equation 4-6. This equation also yields an estimate of the adjustment-cost function. It implies that total adjustment costs, $A$, are given by

$$
\begin{array}{ll}
A=16.1\left(\frac{I}{K}-0.088\right)^{2} K \text { when } \frac{I}{K} \geq 0.088 \\
A=0 \quad \text { when } \frac{I}{K}<0.088 .
\end{array}
$$

28. See Ciccolo, "Four Essays on Monetary Policy," and von Furstenberg, "Corporate Investment." 
The simulation results are not sensitive to the choice of equation 4-6. Similar results are obtained with the other equations in tables 4 and 5 . The growth of the capital stock is determined by the rate of investment. Capital is assumed to depreciate exponentially at 10 percent a year. A final technological assumption is that firms maintain a constant ratio of inventory to output. This assumption is consistent with the historical constancy of the inventory-sales ratio; it has no impact on the estimated effects of tax reforms, but has a sufficient impact on the estimates of inflation.

\section{FINANCIAL POLICY}

A crucial issue in any study of investment behavior is the specification of corporate financial policy. The usual procedure is to specify that the cost of capital is a weighted average of the cost of debt and equity capital, with weights corresponding to the ratio of debt to equity. An analogous assumption is made here: firms finance a fraction, $b$, of net capital investment with debt. In addition, in the face of inflation they issue debt so as to maintain net indebtedness equal to a fraction, $b$, of the replacement cost of the capital stock. The remainder of investment is financed from retained earnings. Given the paucity of new equity issues, this assumption seems reasonable.

The choice of $b$ is of little consequence for the estimates of the effects of tax reforms. However, because of the deductibility of nominal interest payments it has a large effect on estimates of the impact of inflation. The simulations reported here all assume that $b$ equals 0.25 . This figure is chosen to understate the adverse impact of inflation on capital formation. At book value, the ratio of net financial liabilities to tangible assets in the nonfinancial corporate sector was 19.5 percent at the end of $1980 .{ }^{29} \mathrm{At}$ market value, the figure would have been several percentage points lower. These debt ratios include any increased leverage that has resulted from inflation.

There is reason to believe that this average debt-capital ratio exceeds the relevant marginal debt-capital ratio on investments in plant and equipment. Inventory holdings are heavily financed by bank loans. If it is

29. These figures are derived from the Federal Reserve Board's national balance sheets. Similar values can be obtained from von Furstenberg, "Corporate Investment." 
assumed that 75 percent of inventory holdings are debt financed, the remaining debt represents only 4 percent of the stock of plant and equipment. In analyzing the effects of inflation, it is also important to recall that much of net nonfinancial corporate debt is concentrated among regulated utilities, which are hurt because of the use of historical costs in determining the rate base. For these reasons, it is reasonable to believe that the assumptions in this paper about financial policy will yield lowerbound estimates of the impact of inflation. ${ }^{30}$

In the simulations reported here it is assumed that real interest rates remain constant at 2 percent. The nominal rate rises point for point with the rate of inflation. As explained in the last section, this assumption will lead to underestimates of the effects of the interactions between inflation and taxation.

The real after-tax required rate of return on equity, $\rho$, is taken to be 0.06 . In all the simulations it is held constant. This value is consistent with the stock market's average before-tax real return of 8.5 percent during the 1926-74 period. ${ }^{31}$ The assumption that tax policy and inflation do not affect $\rho$ is crucial to the analysis. It rules out the possibility that investment incentives will be "crowded out" by rising costs of capital.

Tax Parameters. The tax parameters are chosen to mirror closely the current U.S. tax system. The initial values are $\tau=0.46, \theta=0.35, c=$ $0.05, I T C=0.056$, and $\delta^{T}=0.175$, where $\delta^{T}$ is the rate of depreciation for tax purposes on the capital stock. One additional complication is introduced in the simulations: firms are assumed to pay corporate income taxes on FIFO inventory profits. The magnitude of this tax as a fraction of output is estimated as the product of the corporate tax rate and the ratio of the inventory valuation adjustment of the nonfinancial corporate sector to its gross output. From this procedure one can conclude that each point of inflation raises corporate taxes by 0.17 percent of output.

With these specifications, the model given by equations 12 and 13 can be solved numerically to examine the effects of policy shocks. An algorithm is used to find the unique self-validating path along which market

30. Following the previous literature on investment, the effects of inflation or tax reforms on the ratio of debt to equity are ignored. The envelope theorem ensures that to a first-order approximation; this introduces no error.

31. Roger G. Ibbotson and Rex A. Sinquefield, "Stocks, Bonds, Bills, and Inflation: Year-by-Year Historical Returns (1926-1974)." Journal of Business, vol. 49 (January 1976), pp. 11-47. 
valuations accurately reflect the present value of the investments they generate. $^{32}$

Some properties of the model's steady state in the absence of inflation are shown below.
$(V / p K)+b$
$D I V / V$
1.114
0.048
Earnings $/ V$
0.091
$I / K$
0.130
$A / K$
0.028
$A / I$
0.221
$F_{K}$
0.233
Corporate taxes $/\left(F_{K}-\delta^{R}\right)(K)$
0.398
Total taxes $/\left(F_{K}-\delta^{R}\right)(K)-A-(i-\pi) b K$
0.562

Steady-state value

The parameters have been chosen to ensure that the steady state affords a reasonable benchmark for studying tax changes. The before-tax net marginal product of capital is 0.133 when adjustment costs are excluded, and 0.104 when they are included. The latter figure corresponds closely to historical experience. Adjustment costs are estimated to be 22 percent of outlays on investment in the steady state. This estimate is quite sensitive to the assumed rates of growth and depreciation. It is difficult to gauge how realistic this assumption is because adjustment costs are not directly observable. However, the simulation results are insensitive to changes in the assumed adjustment-cost function.

The equilibrium value of Tobin's $q$ is at a benchmark of 1.144 , reflecting the effects of taxes and the marginal adjustment costs associated with growth and replacement. The earnings price ratio and dividend yields also correspond well with historical experience.

\section{Inflation, Corporate Investment, and Market Valuation}

The model of investment and market valuation described in the preceding section is now used to evaluate the impact of inflation on the nonfinancial corporate sector. Four separate nonneutralities of the tax system

32. Calculation of the equilibrium path in a model of this type requires the solution of a two-point boundary-value problem. This is done using the algorithm developed in David Lipton and others, "Multiple Shooting in Rational Expectations Models," Technical Working Paper 3 (National Bureau of Economic Research, August 1980). 
lead to real effects of inflation. ${ }^{33}$ First, historical cost depreciation causes inflation to raise the effective corporate tax rate. Note that the understatement of depreciation for tax purposes depends on the entire history of the inflation rate, not just on its current level. In 1979, using historical cost depreciation rather than replacement cost raised corporate tax liabilities by $\$ 24.0$ billion, or 34.4 percent of actual tax liabilities. Second, firms that use FIFO inventory accounting incur additional tax liabilities on their nominal inventory profits. The size of this effect varies with the inflation rate. In the same year, tax liabilities were increased by $\$ 19$ billion, or 27 percent of actual tax payments because of such inventory profits. Third, firms are permitted to deduct nominal rather than real interest payments for tax purposes. In other words, they are not taxed on the capital gain that occurs as inflation erodes the value of their outstanding debt. $^{34}$ This tends to offset the effects of historical cost depreciation and nominal inventory accounting. The 1979 tax savings due to the deductibility of nominal interest payments totaled $\$ 19.9$ billion. Note that the effects of historical cost depreciation and FIFO inventory accounting greatly exceed the value of nominal interest deductibility. Fourth, the taxation of nominal rather than real capital gains leads to an increase in the before-tax return on equity required by investors. This effect is potentially quite large. Nominal capital gains on the corporate capital stock totaled $\$ 178.7$ billion in 1979 , implying an extra tax liability of about $\$ 10$ billion. $^{35}$

\section{THE EFFECTS OF INFLATION}

On balance, these effects imply that inflation substantially increases the effective tax rate on corporate equity. Martin Feldstein has suggested that this could provide an explanation for the observed decline in the

33. These nonneutralities are discussed in more detail in Lawrence H. Summers, "Inflation and the Valuation of Corporate Equities," unpublished, August 1980. Evidence of their aggregate importance can be found in Feldstein and Summers, "Inflation and the Taxation of Capital Income."

34. This discussion and calculation ignore the one-time capital gains firms realize on the revaluation of their long-term debt when the inflation rate rises. The effect can be substantial for some firms (see Summers, "Inflation and Equities"). It is not difficult to show that this omission has no influence on the estimates of the effect of inflation on investment because the effects on existing debt are inframarginal.

35. These capital gains can be masked by downward recapitalization of the market caused by unexpected increases in the rate of inflation. 
stock market. ${ }^{36}$ This conclusion has been challenged by Hendershott, Fama and Gibbons, and Modigliani and Cohn. ${ }^{37}$ But none of these analyses takes account of the endogeneity of capital accumulation and its impact on market valuation; nor do they recognize that taxes complicate the determination of the long-run relation between market valuation and the replacement cost of the capital stock. Feldstein alone considers the implications of his analysis for the long-run growth of the corporate sector, but he does not consider the nature of the adjustment path after an inflation shock.

Before turning to the results, one qualification must be reiterated. The assumption is maintained throughout that inflation has no impact on the real after-tax rate of return required by equity owners. This assumption is open to question. Many observers have argued that inflation reduces real after-tax interest rates and so should also be assumed to reduce required after-tax returns on equity. The results will depend critically on adopting the former assumption. This issue is examined in detail in the last section of the paper.

The effect of inflation on market valuation and investment can be estimated by simulating the effects of an unexpected permanent increase from 0 to 8 percent in the rate of inflation. The paths of the variables of interest are shown in table 6 . All variables are measured as percentage changes from the benchmark steady-state values with no inflation. The results indicate that inflation can have a great influence on capital accumulation in the corporate sector. The immediate effect of an 8 percent inflation shock is to reduce the value of the stock market by 15.1 percent. This is associated with a 10.2 percent reduction in the rate of investment.

As the ratio of capital to output subsequently declines, the before-tax marginal product of capital rises, and the stock market values tend to rise relative to the replacement cost of the capital stock. In the long run, an 8 percent rate of inflation reduces the capital stock by 28.0 percent and

36. Martin Feldstein, "Inflation, Tax Rules, and the Stock Market," Journal of Monetary Economics, vol. 6 (July 1980), pp. 309-31.

37. Patric H. Hendershott, "The Decline in Aggregate Share Values: Inflation and Taxation of the Returns from Equities and Owner-Occupied Housing," Working Paper 370 (National Bureau of Economic Research, July 1979); Eugene F. Fama and Michael R. Gibbons, "Inflation, Real Returns and Capital Investment," unpublished, Graduate School of Business, University of Chicago, May 1980; and Franco Modigliani and Richard A. Cohn, "Inflation, Rational Valuation, and the Market," Financial Analysts Journal, vol. 35 (March-April 1979), pp. 24-44. 
Table 6. Response of Stock Market Valuation and Investment of Nonfinancial Corporations to an Increase in Inflation from Zero to Eight Percent

Percent

\begin{tabular}{cccccccc}
\hline & \multicolumn{3}{c}{ FIFO effects included } & & \multicolumn{3}{c}{ FIFO effects excluded } \\
\cline { 2 - 3 } \cline { 7 - 8 } Year & $\Delta(V / p)$ & $\Delta I$ & $\Delta K$ & & $\Delta(V / p)$ & $\Delta I$ & $\Delta K$ \\
\hline 1 & -15.1 & -10.2 & 0.0 & & -7.5 & -5.7 & 0.0 \\
2 & -16.7 & -11.0 & -1.3 & & -8.8 & -6.2 & -0.7 \\
3 & -17.9 & -11.7 & -2.6 & & -9.8 & -6.6 & -1.4 \\
4 & -18.9 & -12.5 & -3.7 & -10.6 & -7.1 & -2.1 \\
5 & -19.7 & -13.2 & -4.9 & -11.2 & -7.5 & -2.7 \\
10 & -22.2 & -16.2 & -9.7 & -13.0 & -9.2 & -5.5 \\
15 & -23.6 & -18.5 & -13.5 & -13.9 & -10.4 & -7.6 \\
20 & -24.8 & -20.6 & -16.5 & -14.7 & -11.8 & -9.4 \\
50 & -27.9 & -26.3 & -25.2 & -16.6 & -15.1 & -14.5 \\
Steady state & -29.1 & -28.0 & -28.0 & -17.3 & -16.1 & -16.1 \\
\hline
\end{tabular}

Source: Simulations by the author.

a. Calculations by the author, as described in the text. All figures refer to percentage changes from the bench mark steady state without inflation.

the value of the stock market by 29.1 percent. Transition is quite slowonly three-fourths of the ultimate adjustment of the capital stock takes place within twenty years. The effects of inflation on the rate of investment actually increase over time, reflecting the reduced need for replacement investment as the capital stock contracts.

These findings suggest that inflation accounts for a significant part of the decline in the stock market and the investment that has occurred during the past decade. After ten years of 8 percent inflation, the stock market value of capital is about 23 percent lower in real terms than it would have been in the absence of inflation. The 16.2 percent decline in gross investment indicated by the simulations is far larger than what has actually taken place. The relatively strong performance of investment probably reflects the increases in the 1970s of the investment tax credit and the acceleration of tax depreciation as well as some of the other factors such as energy discussed at the beginning of the paper. ${ }^{38}$ The tax measures should have been a significant spur to investment but not to $q$.

There are some reasons to believe that the additional taxes incurred as a result of FIFO inventory accounting do not discourage investment in

38. The investment tax credit was suspended at the beginning of the decade and applied at a rate of 9 percent in 1979. The accelerated depreciation rate system introduced in 1971 has shortened depreciation lifetimes by about 20 percent. 
plant and equipment. It is argued that taxes on inventory holdings should have no direct impact on the return to plant and equipment investment and so should not affect these investment decisions. It has also been argued that the taxes are voluntary and so are unlikely to be paid if they impose a burden. The last three columns of table 6 examine the impact of inflation under the assumption that all firms use LIFO (last in, first out) accounting and so no taxes are levied on inventory profits. The results indicate that the impact of inflation is approximately halved if inventory effects are excluded. The long run-capital stock is reduced by 16.1 percent with no FIFO effects, compared to 28.0 percent when these effects are included.

It is surely inadvisable to ignore completely the effects of FIFO on corporate tax burdens. The fact that taxes are voluntary does not mean that they impose no burden or have no incentive effects. Presumably managers see some benefit to paying the tax or else it would not be paid. Increases in the rate of inflation erode the surplus the firm receives by using FIFO and so impose a burden. The practice of looking at actual firm behavior rather than the tax situation of a hypothetical tax-minimizing firm is well established in the literature on investment. The usual practice is to assume that firms only slowly learn to take advantage of accelerated depreciation. The "involuntary taxes" firms pay as they learn are assumed to have real effects on investment. The argument that inventory taxes affect only inventory investment and not fixed investment is not persuasive. Firms undertake fixed investment in order to expand their capacity to produce output. Any reasonable specification of production and sales technology will imply that increases in output lead to greater inventory holding. Taxes on inventories may thus discourage capacity-creating investment. The particular technological assumption made here that the inventory-output ratio is constant may not be exactly accurate. However, there is no evidence that the elasticity of substitution between inventories and capital is very large. As long as this is the case, the assumption of a constant ratio will be approximately correct. The only available empirical evidence provides further support for the assumption that inventory taxes discourage capital accumulation. ${ }^{39}$

39. Robert McDonald shows that investment in industries with high FIFO inventories investment is discouraged by inflation relative to investment in other industries. See his "Inflation and the Industrial Composition of Investment," unpublished, Massachusetts Institute of Technology, 1981. 
These considerations suggest that the estimates of the impact of inflation in the first three columns of table 6 are the most plausible. This conclusion is reinforced by recalling that the financial policy parameters were set to understate the estimated effects of inflation.

The results in table 6 indicate that inflation may have a great impact on capital accumulation. An increase in the rate of inflation from 0 to 8 percent slows the rate of growth of the capital stock by about 1 percent a year for the first decade. This should be expected to reduce the rate of growth of productivity and real wages by 0.25 percent each year. According to these calculations, in the long run inflation reduces the level of both output and wages in the corporate sector by about 6 percent from the levels that would have been reached in the absence of inflation.

It is frequently proposed that the nonneutralities of the tax system that produce these effects can be remedied through indexation. The effects of inflation on the stock market and investment under various partial indexing schemes are shown in table 7 . The table also makes it possible to examine the relative importance of the various distortions associated with inflation. Full indexing, which makes the tax system completely neutral to inflation, is not shown in the table.

Indexing depreciation allowances and the cost of goods sold for the purpose of calculating inventory profits while not recognizing for tax purposes the profits firms realize on their outstanding debt would result in inflation significantly encouraging rather than discouraging investment. With such indexing, an 8 percent increase in the expected rate of inflation would raise the stock market by about 8 percent in the short run. This is because the advantage from the deduction of nominal interest payments is greater than the burden arising from the taxation of inflation-induced capital gains. The results in table 7 imply that indexing depreciation allowances would reduce the equilibrium ratio of the stock market value to the replacement cost of the capital stock because such indexation reduces the effective price of new capital goods.

The effects of inflation with full indexing at the corporate level are shown in the third and fourth columns of table 7 . The remaining distortion, taxation of nominal capital gains, leads to a reduction in stock market values and capital formation. The capital gains distortion alone is sufficient to cause 8 percent inflation to reduce the steady-state capital stock by approximately 10 percent.

Indexation at the individual level but not at the corporate level is con- 
Table 7. Effects of Eight Percent Inflation with Indexation on the Stock Market Value and Investment of Nonfinancial Corporations ${ }^{\mathrm{a}}$

Percent

\begin{tabular}{|c|c|c|c|c|c|c|}
\hline \multirow[b]{2}{*}{ Year } & \multicolumn{2}{|c|}{$\begin{array}{l}\text { Indexed depreciation } \\
\text { and inventory }\end{array}$} & \multicolumn{2}{|c|}{$\begin{array}{l}\text { Full corporate } \\
\text { indexing }\end{array}$} & \multicolumn{2}{|c|}{$\begin{array}{l}\text { Indexed capital } \\
\text { gains }^{\mathrm{d}}\end{array}$} \\
\hline & $\Delta V$ & $\Delta I$ & $\Delta V$ & $\Delta I$ & $\Delta V$ & $\Delta I$ \\
\hline 1 & 6.3 & 9.6 & -5.3 & -3.2 & -10.5 & -7.5 \\
\hline 2 & 6.9 & 9.6 & -5.5 & -3.4 & -12.0 & -8.1 \\
\hline 3 & 7.5 & 10.9 & -5.7 & -3.7 & -13.1 & -8.7 \\
\hline 4 & 8.1 & 11.9 & -5.9 & -3.9 & -14.0 & -9.3 \\
\hline 5 & 8.6 & 12.8 & -6.1 & -4.2 & -14.7 & -9.8 \\
\hline 10 & 10.8 & 18.7 & -6.8 & -5.2 & -16.8 & -12.1 \\
\hline 15 & 12.6 & 20.7 & -7.3 & -6.0 & -18.0 & -13.8 \\
\hline 20 & 13.8 & 22.6 & -7.7 & -4.3 & -18.9 & -15.5 \\
\hline 50 & 17.8 & 26.1 & -9.7 & -9.3 & -21.7 & -20.1 \\
\hline Steady state & 19.1 & 27.3 & -11.1 & -10.6 & -23.2 & -21.3 \\
\hline
\end{tabular}

Source: Simulations by the author.

a. All numbers shown are percentage changes from the benchmark steady state without inflation.

b. It is assumed that replacement cost depreciation is allowed on existing assets and new investments.

c. It is assumed that firms are permitted to deduct only real interest payments for tax purposes in addition to the indexing described in note $b$.

d. Only real capital gains are taxed. The simulation in these two columns assumes no indexation at the corporate level.

sidered in the last two columns in the table. The results show that corporate tax nonneutralities are responsible for a large fraction of inflation's impact on capital formation. They clearly indicate that, contrary to assertions made by some authors, the effects of inflation on inventory profits and depreciation allowances more than offset the deductibility of nominal interest payments. This is because the analysis takes explicit account of the cumulative understatement of depreciation allowances that accompanies inflation in the steady state.

\section{TAX REFORM AND CORPORATE INVESTMENT}

Measures to spur investment through tax reduction command widespread support. Little is known, however, about the relative effectiveness of alternative policies. Investment incentives can be roughly divided into three categories-reductions in the effective price of new capital goods through the investment tax credit or accelerated depreciation, reductions in the corporate tax rate, and reductions in taxes on the return to investment at the personal level. 
Much of the discussion of corporate tax reform has focused on its likely impact on investment; but issues of horizontal and vertical equity should also be considered. Although unsophisticated observers focus on the distinction between tax relief for business and for individuals, all taxes are ultimately borne by individuals in their role as labor suppliers, consumers, or suppliers of capital. The corporation tax should be thought of as one portion of the tax on capital; and for the study of equity as well as incentives, it should be integrated with the personal tax. The change in the value of the stock market immediately following a tax change provides a direct measure of the present value of the tax change to the suppliers of equity capital, taking both the corporate and personal taxes into account. The change in market value thus seems a natural candidate for measuring the incidence of capital tax reform. Good tax reform should minimize windfall gains and losses.

The influence of tax policy on the stock market has important consequences for vertical equity. Most corporate equity is owned directly or indirectly by the wealthy. About 75 percent is held directly by individuals, and about half of this is held by families with incomes in the top 1 percent of the income distribution. ${ }^{40}$ This presumably understates the true concentration because much of the remainder of this 75 percent is held by individuals with deceptively low reported incomes due to tax shelters or temporarily low income. The remaining stock is mostly held by pension funds, foreigners, and insurance companies. Because almost all pension plans offer defined benefits, the pension's assets are ultimately owned not by the beneficiaries but by the share owners in the corporations with pension liabilities. Hence this stock is also primarily owned by the affluent. The distributional consequences of ownership by insurance companies and foreigners are less clear. But the conclusion seems inevitable-a taxinduced change in profitability that shows up in the stock market falls almost entirely on the rich. If the tax stimulation of investment is the primary social objective, not redistribution to the rich, tax incentives should minimize the windfall gains to existing shareholders.

An increase in the investment tax credit is examined in table 8. Results for accelerated depreciation would be analytically similar. The first three columns of the table consider the effects of an immediate doubling of the

40. These figures are all based on information or dividend income derived from the TAXSIM file of the National Bureau of Economic Research with the assistance of Daniel Feenberg. 
Table 8. Comparison of an Immediate and an Anticipated Increase in the Investment Tax Credit ${ }^{\mathrm{a}}$

Percent

\begin{tabular}{cccccccc}
\hline & \multicolumn{3}{c}{ Immediate } & & \multicolumn{3}{c}{ Anticipated } \\
\cline { 2 - 3 } \cline { 6 - 8 } Year & $\Delta(V / p)$ & $\Delta I$ & $\Delta K$ & & $\Delta(V / p)$ & $\Delta I$ & $\Delta K$ \\
\hline 1 & 4.8 & 5.5 & 0.0 & & 3.8 & 0.3 & 0.0 \\
2 & 5.2 & 6.0 & 0.7 & & 4.3 & 2.8 & 0.3 \\
3 & 5.5 & 6.5 & 1.4 & & 4.8 & 3.2 & 0.6 \\
4 & 5.9 & 6.9 & 2.0 & & 5.3 & 6.2 & 0.9 \\
5 & 6.2 & 7.4 & 2.6 & & 5.6 & 6.6 & 1.6 \\
10 & 6.2 & 9.4 & 5.4 & & 7.0 & 8.8 & 4.5 \\
15 & 8.4 & 11.2 & 7.7 & & 8.1 & 10.7 & 7.0 \\
20 & 9.1 & 12.2 & 9.4 & & 8.9 & 11.8 & 8.9 \\
50 & 11.5 & 16.2 & 15.3 & & 11.4 & 16.1 & 15.1 \\
Steady state & 12.4 & 17.3 & 17.3 & & 12.4 & 17.3 & 17.3 \\
\hline
\end{tabular}

Source: Simulations by the author.

a. In both simulations the investment tax credit is doubled, with its effective rate rising from 0.056 to 0.112. The anticipated change takes place four years after announcement. The numbers in the table are percentage deviations from steady state with 8 percent inflation.

investment tax credit from 0.056 to 0.112 . The results indicate that the credit has important effects on investment and a considerable effect on market value-approximately ten times the one-year tax expenditure. The first year effect of doubling the credit is to raise the stock market value by 4.8 percent and the level of investment by 5.5 percent. Even though this is a substantial windfall to existing stockholders, it is small compared to the windfall effects of other tax incentives. Because increases in the credit apply only to new investment, they provide more stimulus to investment per dollar of forgone revenue than tax changes that apply to old as well as new capital. The same can be said about accelerated depreciation. In the long run the capital stock is increased by 17.3 percent. These estimates are fairly close to those obtained by others using conventional investment equations; however, the results obtained here imply that the process of adjustment is much slower than is usually assumed. The half-life of the adjustment process is close to twenty years.

The last three columns of the table consider the effect of the announcement of a future investment tax credit. Paradoxically, an announcement of a future tax credit increases investment even before the credit takes effect. The announcement that the credit will double in four years is estimated to raise the market value by 3.8 percent in the first year, and to increase investment by 2.8 percent in the second year. It might have been expected that investment would decline before the credit went into 
Table 9. Comparison of an Immediate and an Anticipated Reduction of the Corporate Tax Rate

Percent

\begin{tabular}{cccccccc}
\hline & \multicolumn{3}{c}{ Immediate } & & \multicolumn{3}{c}{ Anticipated } \\
\cline { 2 - 3 } \cline { 7 - 8 } Year & $\Delta(V / p)$ & $\Delta I$ & $\Delta K$ & & $\Delta(V / p)$ & $\Delta I$ & $\Delta K$ \\
\hline 1 & 13.3 & 3.2 & 0.0 & & 10.5 & 6.0 & 0.0 \\
2 & 13.5 & 3.4 & 0.4 & & 11.8 & 6.9 & 0.8 \\
3 & 13.7 & 3.7 & 0.8 & & 13.1 & 7.8 & 1.5 \\
4 & 13.8 & 3.9 & 1.1 & & 14.5 & 4.7 & 2.3 \\
5 & 14.0 & 4.2 & 1.4 & & 14.6 & 4.9 & 2.6 \\
10 & 14.7 & 5.2 & 2.4 & & 15.1 & 5.9 & 3.9 \\
15 & 15.3 & 6.2 & 4.2 & & 15.6 & 6.8 & 5.0 \\
20 & 15.7 & 6.7 & 5.1 & & 15.9 & 7.1 & 5.7 \\
50 & 16.9 & 8.7 & 8.1 & & 17.0 & 8.8 & 8.2 \\
Steady state & 17.4 & 9.0 & 9.0 & & 17.4 & 9.0 & 9.0 \\
\hline
\end{tabular}

Source: Simulations by the author.

a. In both simulations the corporate tax rate is reduced from 0.46 to 0.40 . The anticipated change takes place four years after announcement. The numbers in the table are percentage deviations from steady state with 8 percent inflation.

effect and would jump immediately afterward. While there is incentive to postpone investment to take advantage of the tax credit, the desire for higher future investment itself makes current investment more attractive. Current investment not only increases output, but also reduces the adjustment costs associated with the higher future investment because it makes the future capital stock larger. If marginal adjustment costs were lower, this effect would not predominate.

The effects of reductions in the corporate tax rate are examined in table 9. An immediate rate reduction from 0.46 to 0.40 is contrasted with an announcement that in the fourth year such a tax cut will take place. The measures are equivalent in the long run and both raise the steadystate capital stock by 9 percent. They increase the long-run value of the stock market by almost twice as much as this increase in the capital stock. This is because the reduced corporate tax lowers the value of accelerated depreciation and the immediate expensing of adjustment costs, thereby raising the after-tax cost of new capital goods.

The simulations show that the announcement of a future cut has a significantly greater short-run impact on investment than immediate implementation of the cut. The former raises the capital stock by 2.3 percent after four years; the latter, by only 1.1 percent, even though immediate implementation has a greater initial impact on market value. Again, this reflects the effects of accelerated depreciation and the expensing of ad- 
justment costs. Firms find it optimal to accelerate their investment plans to take account of the lower effective price of capital goods-resulting from larger tax savings on costs and depreciation-that prevails before the tax reduction actually takes place. This implies that if the goal of the corporate tax rate reduction is to increase capital formation, the measure should be announced well in advance of the enactment. Similar considerations suggest the possibility that a temporary increase in the corporate tax rate would actually spur investment by encouraging firms to incur the associated tax-deductible costs while rates are high.

These findings have important policy implications. They indicate that a policy of announcing a future reduction in corporate taxes will spur investment with no current revenue loss. Indeed, the effect on investment would actually be enhanced if corporate taxes were raised immediately and then cut. By combining temporary corporate tax rate increases with temporary increases in the investment tax credit or accelerated depreciation, investment stimulus could be provided at no short-run budgetary cost.

Corporate tax rate changes have large windfall effects on the stock market, however, because they affect the inframarginal return on existing capital as well as the incentive to acquire new capital goods. In the short run, changes in the corporate tax have three to four times the effect on market value as does a tax credit with the same effect on investment; in the long run, the ratio of the stock market effects is almost two to one. This may explain why the business community is typically so eager for a reduction in the corporate tax rate, even though it is not a strong investment stimulus.

Most previous analyses of investment incentives have neglected the role of individual taxes. The effects of two reforms in the individual tax system are considered in table 10. Eliminating capital gains taxes would raise the stock market value by 4.4 percent in the short run. Because it would increase the advantages to the firm of retaining earnings, the impact on investment is large, and the investment stimulus is larger relative to the increase in $V$ than it is for any other stimulus considered. In the long run, it would raise the capital stock by 17.7 percent and the market value by only two-thirds as much. The transition, like the adjustment path following any tax change in the model, is gradual, with only half the adjustment occurring within the first decade.

The second reform considered in the table is an announcement that 
Table 10. Reforms in Individual Taxes

Percent

\begin{tabular}{cccccccc}
\hline & \multicolumn{3}{c}{$\begin{array}{c}\text { Elimination of the capital } \\
\text { gains tax }\end{array}$} & & \multicolumn{3}{c}{$\begin{array}{c}\text { Anticipated elimination of the } \\
\text { dividend tax }\end{array}$} \\
\cline { 2 - 3 } \cline { 6 - 8 } Year & $\Delta(V / p)$ & $\Delta I$ & $\Delta K$ & & $\Delta(V / p)$ & $\Delta I$ & $\Delta K$ \\
\hline 1 & 4.4 & 6.0 & 0.0 & & 42.6 & 24.6 & 0.0 \\
2 & 4.8 & 6.5 & 0.7 & & 48.4 & 29.1 & 3.2 \\
3 & 5.2 & 7.0 & 1.5 & & 54.5 & 33.9 & 6.5 \\
4 & 5.5 & 7.4 & 2.1 & & 61.1 & 6.4 & 10.0 \\
5 & 5.8 & 7.9 & 2.8 & & 60.5 & 6.6 & 9.6 \\
10 & 7.1 & 10.0 & 5.7 & & 58.5 & 5.4 & 7.7 \\
15 & 8.2 & 11.8 & 8.2 & & 57.6 & 4.6 & 6.2 \\
20 & 8.8 & 12.8 & 10.0 & & 56.7 & 3.5 & 4.4 \\
50 & 11.1 & 16.8 & 15.8 & & 54.6 & 1.1 & 1.4 \\
Steady state & 11.9 & 17.7 & 17.7 & & 53.8 & 0.0 & 0.0 \\
\hline
\end{tabular}

Source: Simulations by the author.

a. The numbers in the table are percentage changes relative to steady state with 8 percent inflation. Dividend taxes are eliminated four years after announcement.

the dividend tax will be eliminated after four years. As explained above, changes in the dividend tax rate have no effect on a steady-state capital intensity. The announcement that a dividend tax reduction will occur, however, gives firms a strong incentive to defer paying dividends. In the model, this is done by accelerating investment. In the simulation the announcement effect raises investment by 24.6 percent and stock market value by 42.6 percent in the first year. Only a stock market effect remains in the long run.

One clear lesson to be derived from the theory developed in this paper is that dividend relief is a very poor form of investment incentive. In the long run, dividend taxes are neutral unless firms issue new equity, which is relatively unimportant in practice. Thus, reducing the dividend tax has small incentive effects and serves primarily to provide a windfall to the owners of corporate capital. ${ }^{41}$ A natural corollary is that reducing the tax rates of the individuals in high tax brackets is likely to have more effect on market values than on investment.

Taken together, the results indicate the large scope available to tax policy for affecting capital accumulation in the long run. Politically con-

41. These arguments were first put forth by Alan J. Auerbach in his "Share Valuation and Corporate Equity Policy," Journal of Public Economics, vol. 11 (June 1979), pp. 291-305. 
Table 11. Comparison of a Permanent and a Temporary Reduction in the Investors' Required Rate of Returna

Percent

\begin{tabular}{cccccccc}
\hline & \multicolumn{3}{c}{ Permanent reduction } & & \multicolumn{3}{c}{ Temporary reduction $^{\mathrm{b}}$} \\
\cline { 2 - 3 } Year & $\Delta(V / p)$ & $\Delta I$ & $\Delta K$ & & $\Delta(V / p)$ & $\Delta I$ & $\Delta K$ \\
\hline 1 & 14.7 & 8.4 & 0.0 & & 2.7 & 1.5 & 0.0 \\
2 & 15.3 & 9.2 & 1.1 & & 2.0 & 1.2 & 0.2 \\
3 & 15.9 & 10.0 & 2.2 & & 1.1 & 0.7 & 0.4 \\
4 & 16.5 & 10.7 & 3.2 & & 0.2 & 0.1 & 0.4 \\
5 & 17.0 & 11.4 & 4.2 & & 0.2 & 0.1 & 0.4 \\
10 & 19.1 & 14.5 & 8.6 & & 0.1 & 0.1 & 0.3 \\
15 & 20.8 & 17.2 & 12.3 & & 0.1 & 0.1 & 0.3 \\
20 & 21.9 & 19.0 & 15.1 & & 0.1 & 0.0 & 0.2 \\
50 & 25.7 & 25.1 & 24.2 & & 0.0 & 0.0 & 0.0 \\
Steady state & 27.1 & 27.2 & 27.2 & & 0.0 & 0.0 & 0.0 \\
\hline
\end{tabular}

Source: Simulations by the author.

a. In each case the change from a reduction in $\rho$ from 0.06 to 0.05 is reported. The numbers in the table indicate the percentage changes from steady state with 8 percent inflation.

b. The rate of return is reduced for only three years. Investors know that the reduction is transitory.

ceivable measures, such as the removal of capital gains taxes or the allowance of more rapid or indexed depreciation, would have a great impact on long-run capital intensity. Measures can be designed to stimulate investment with a relatively low cost in forgone government revenue. These simulations also highlight the dangers of indiscriminate tax cutting. The incentive effects of announced and unannounced cuts vary greatly among tax measures; thus careful policy design can increase the investment stimulus per dollar of lost government revenue.

\section{Taxation and the Required Rate of Return}

The analysis thus far has assumed that neither taxes nor inflation affect the real after-tax rate of return required by investors in the corporate sector. Similar assumptions are common in partial equilibrium analyses of the effects of tax changes on the level of investment. However, the treatment of the required rate of return is crucial to any estimate of tax effects on investment. An endogenous response of the required rate to changes in taxes or to induced changes in the market value of capital and wealth could in principle significantly alter the results. Table 11 indicates 
that permanent and temporary changes in the rate of return required by corporate investors have substantial effects. A permanent reduction in the real after-tax required rate of return from 0.06 to 0.05 would immediately raise stock market value by 14.7 percent and the level of investment by 8.4 percent. This effect is large; it approaches the negative impact of an 8 percent increase in the rate of inflation. Thus neglecting any effects of tax policy on the required rate of return is likely to lead to significant overestimates of policy impacts.

The last three columns of the table shed light on a controversy that has received a great deal of attention. Comparing them with the first three columns shows the different effects of changes in the short- and long-term required rate of return. In the presence of adjustment costs, investment is far more sensitive to the long-term than the short-term rate. This has important implications for the transmission mechanism of general monetary and fiscal policies and underscores the fact that the crucial question is the impact of tax measures on investors' long-term required rate of return, not on their required rate of return over a short horizon.

\section{INVESTMENT AND THE SUPPLY OF FUNDS}

TO THE CORPORATE SECTOR

In analyzing the impact of tax changes and inflation on required rates of return, I adopt a variant of the framework that Martin Feldstein and I developed in earlier research. ${ }^{42}$ As figure 6 illustrates, the required aftertax rate of return, $\rho$, depends on the supply and demand for corporate capital. The $K D$ schedule in the figure demonstrates that, in the long run, firms will demand more capital as the required rate of return declines. The simulations reported in table 11 show that the $K D$ schedule is very flat, and that a reduction in $\rho$ of 1 percentage point increases $K$ by 27 percent. The $K S$ schedule indicates that the supply of capital to the corporate sector depends positively on the real after-tax return received by investors. The assumption maintained thus far - that the after-tax rate of return required by corporate investors is constant-is equivalent to assuming that the $K S$ curve in figure 6 is horizontal. That is, it requires that

42. Martin Feldstein and Lawrence Summers, "Inflation, Tax Rules and the LongTerm Interest Rate," BPEA, 1:1978, pp. 61-109. 
Figure 6. The Determinants of the Required Rate of Return

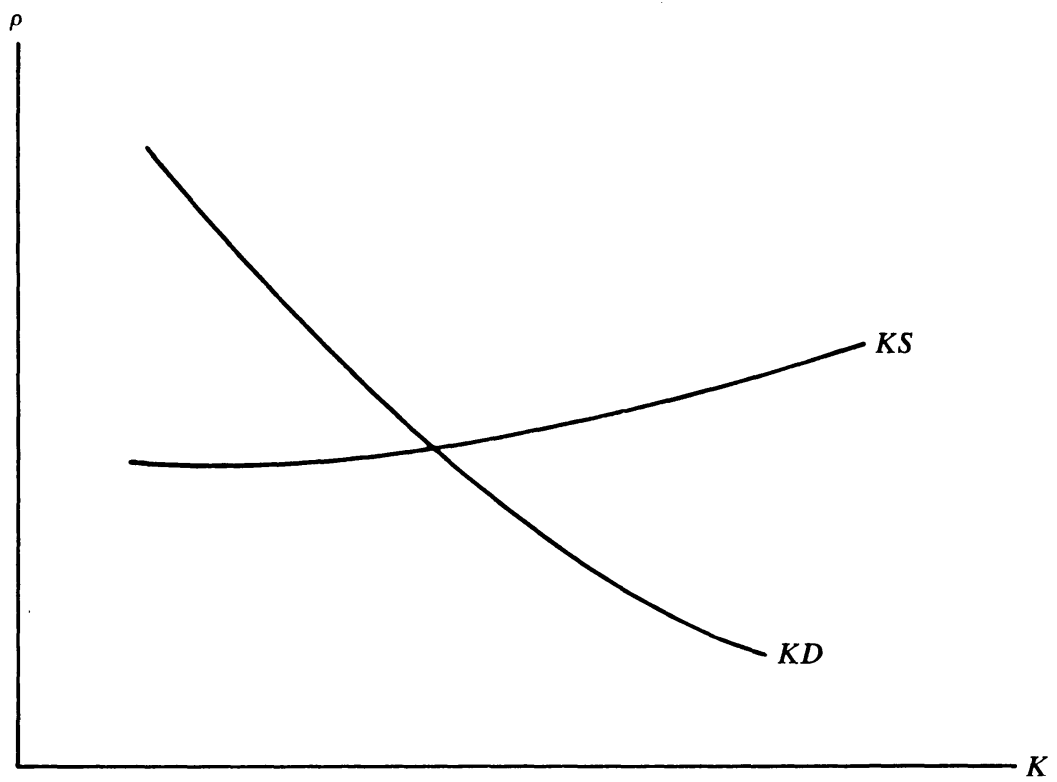

the supply of funds to the corporate sector is perfectly elastic..$^{43}$ Unless this condition is satisfied, investment incentives will be partially crowded out by increases in the rate of return required by corporate investors. In the limiting case in which the supply of funds to the corporate sector is completely inelastic and the $K S$ curve in figure 6 is vertical, investment stimuli will have no effect on capital accumulation.

It is therefore crucial to assess the elasticity of the supply of funds to the corporate sector. This elasticity should not be confused with the elasticity of total saving with respect to the rate of return; analysis of the problem in these terms ignores portfolio reallocations. Even if the supply of total saving were completely insensitive to rates of return, the supply of funds to the corporate sector might be highly elastic in response to changes in the relative rates of return on corporate and noncorporate capital. The crucial issue here is the size of the corporate sector relative to the entire capital market. If the corporate sector is small relative to the capital market, the assumption that it faces an exogenously determined rate of return is quite reasonable.

43. An alternative assumption is that the supply of funds to the corporate sector is not perfectly elastic but is shifted outward by tax reforms. This possibility is analyzed below. 
The national balance sheets prepared by the Federal Reserve Board reveal that the nonfinancial corporate sector accounts for a surprisingly small fraction of net wealth. At the end of 1980, the market value of equity in this sector was $\$ 1,246.9$ billion. This represented only 13 percent of the net worth of all domestic holders of wealth. To some extent this low figure reflects the depressed value of the stock market and ignores corporate debt. At replacement cost, the value of the tangible assets in the corporate sector was $\$ 2,190.8$ billion, or 23 percent of domestic net worth. These figures suggest that the corporate sector plays a relatively small role in the domestic capital market because a sizable fraction of the national wealth is held in the form of housing and noncorporate capital. ${ }^{44}$

The U.S. corporate sector appears even less dominant in the context of world capital markets. U.S. funds flow out of the country, and foreign funds flow in, in response to changes in the attractiveness of investment in the United States. ${ }^{45}$ The potential importance of these flows is indicated by the 25 percent of net investment by U.S. corporations that takes place abroad. ${ }^{46}$ Because the U.S. corporate sector represents only a small fraction of the total demands on the world capital markets, it seems reasonable to adopt the competitive assumption that the supply of funds to the corporate sector is highly elastic.

Several objections might be made to the analysis of this supply of funds. Some of the tax changes that have been considered would affect investments outside the corporate sector. Hence, focusing only on the size of this sector would lead to an underestimate of its effects throughout the economy. However, the total of all plant and equipment valued at replacement cost accounts for less than one-third of total U.S. net worth, and a much smaller fraction of world net worth. Even if some other assets were affected in parallel with corporate assets, the total would not be large relative to total net worth. It might also be argued that markets are segmented, or that corporate capital is an imperfect substitute for other assets, so it is

44. In a recent work I illustrate how portfolio reallocations between owneroccupied housing and corporate stock induced by tax effects help to account for the boom in housing prices and stock market slump that occurred during the 1970s. See Lawrence H. Summers "Inflation, the Stock Market and Owner Occupied Housing," American Economic Review, vol. 71 (May 1981), Papers and Proceedings, 1980), pp. 429-34.

45. For example, see the paper by Jeffrey Sachs in this issue.

46. This figure appears in C. Fred Bergsten, Thomas Horst, and Theodore H. Moran, American Multinationals and American Interests (Brookings Institution, 1978). 
not reasonable to look at the corporate sector relative to the entire capital market. Segmentation seems untenable in light of the data on the distribution of corporate stock discussed above. Most stock is held by wealthy individuals who hold a variety of other assets in their portfolios. Although imperfect substitutability is a theoretical possibility, empirical studies appear to show that portfolio allocations are sensitive to tax considerations. ${ }^{47}$

The analysis thus far has assumed that the total supply of savings is insensitive to the rate of return. Even if portfolio allocations were completely inflexible, the supply of funds to the corporate sector would be highly elastic if overall saving were sufficiently sensitive to interest rates. Some recent theoretical arguments have suggested it may be, challenging the widespread belief that the saving rate is interest-inelastic. The "infinite horizon" model of intertemporal consumption decisions implies that saving is infinitely elastic in the long run. ${ }^{48}$ Elsewhere I have argued that plausible life-cycle formulations imply a very high interest elasticity of saving. ${ }^{49}$ Whatever the theoretical rationale for a high interest elasticity of saving, the available empirical evidence is weak and inconclusive. ${ }^{50}$

If either portfolio allocations or total saving is responsive to rates of return, the supply of funds to the corporate sector is likely to be highly elastic. The implications for policy directed at stimulating investment in

47. See, for example, Martin Feldstein, "Personal Taxation and Portfolio Composition: An Econometric Analysis," Econometrica, vol. 44 (July 1976), pp. 631-50.

48. Recent empirical research suggests that this model may be appropriate because bequests motivate a large fraction of capital accumulation. See, for example, Laurence Kotlikoff and Lawrence H. Summers, "The Importance of Intergenerational Transfers in Aggregate Capital Accumulation," forthcoming in Journal of Political Economy, August 1981.

49. Lawrence H. Summers, "Taxation and Capital Accumulation in a Life Cycle Growth Model," forthcoming in American Economic Review, September 1981. The result occurs because of the important effect of changes in the rate of return on the discounted value of future labor income. This conclusion echoes earlier work. Calculations reported by James Tobin suggest a large long-run response of saving to interest rates. See his "Life Cycle Saving and Balanced Growth," in William Fellner and others, Ten Economic Studies in the Tradition of Irving Fisher (John Wiley, 1967), pp. 231-56.

50. Michael Boskin, in the first study to use a measure of the real after-tax interest rate as an explanatory variable, found an interest elasticity of saving of about 0.4 . While his estimate has been widely challenged as too high, there are reasons to believe that a study of its type may underestimate the actual response to a permanent change in tax policy: his data come from transitory variations in interest rates, and he takes no account of possible wealth effects arising from changes in interest rates. See Michael J. Boskin, "Taxation, Saving, and the Rate of Interest," Journal of Political Economy, vol. 86 (April 1978), pt. 2, pp. S3-S27. 
plant and equipment are clear-measures to encourage these forms of investment are likely to be much more effective than those directed at increasing saving in general. The high elasticity of supply of funds to the corporate sector suggests that only a small fraction of any policy-induced increase in saving will find its way into corporate investment, and that reduced government deficits, or tax incentives directed at individual savers, will not greatly affect corporate capital formation. The analysis also implies that measures directed specifically at investment in plant and equipment will be successful because any crowding out due to inelasticity in the supply of funds is likely to be minor.

Even if the supply of funds to the corporate sector is not highly elastic, policy could shift the supply curve outward. Most forms of tax relief for corporate capital would do this, since a significant fraction of such relief probably would be retained by corporations. Empirical evidence suggests that individuals do not fully pierce the corporate veil, so that their personal saving does not offset changes in retained earnings by corporations. Furthermore, because most corporate equity is held by the wealthy or by institutions with a very low marginal propensity to consume, a large fraction of any increase in dividends is likely to be saved. Because of these effects, tax incentives to business could actually reduce the required rate of return, depending on how they were financed. ${ }^{51}$

Finally, the government has independent monetary and fiscal policies with which it can manipulate the required rate of return. If crowding out of investment incentives due to a limited supply of savings became a problem, the government could easily reduce the required rate of return with easy money and tight fiscal policies. The question of crowding out is in a sense academic because policy can overcome any tendency in this direction. This point has long been recognized in connection with debates about the effectiveness of fiscal policy in raising appropriate demand.

Strong reasons exist to support the assumption made here that tax policies have little impact on the required rate of return. However, the question is ultimately an empirical one. In a previous work Martin Feldstein and I attempted to gauge the elasticity of the supply of capital to the corporate sector by examining the effects on actual interest rates of changes in the maximum potential interest rate that firms can afford to pay on a

51. If, for example, tax incentives were financed with cuts in government spending or taxes on groups with a high marginal propensity to consume, they would reduce consumption demand tending to depress the required rate of return. 
given investment project. ${ }^{52}$ The results indicate that each 1 percentage point increase in this maximum affordable rate raises interest rates by only 25 basis points, which suggests a high elasticity of supply. It also implies, roughly, that only 25 percent of the stimulus afforded by investment tax incentives is offset by rising required rates of return.

\section{INFLATION AND REQUIRED RATES OF RETURN}

If the supply of funds to the corporate sector is highly elastic, changes in the rate of inflation should have little impact on the real rate of return required by corporate investors. This assumption underlies the simulations in table 6 showing that increases in the rate of inflation greatly reduce the value of the stock market and the level of corporate capital accumulation. A quite different treatment of the required rate of return has been employed in most previous discussions of inflation-tax interactions. ${ }^{53}$ These discussions postulate that a fixed risk premium separates the after-tax returns on stocks and bonds. Because interest rates appear to rise no more than point for point with inflation, real after-tax bond yields fall. And because a fixed spread between bond and stock returns is assumed, a decline in the required rate of return on equity is also implied, and it is frequently quite large. If a 25 percent tax rate on interest income is assumed, 8 percent inflation reduces real after-tax bond yields by 2 percentage points. After allowing for such declines in the rate of return, Hendershott and Gordon argue that inflation is not likely to have an adverse impact on the stock market or capital accumulation. My simulations of changes in the rate of inflation and the required rate of return support their conclusion that a 2 percent reduction in the real rate would offset the other adverse effects of inflation.

The crucial issue, then, is the validity of inferring the required rate of return on equity by adding a constant risk premium to the real after-tax return on bonds. This procedure is not well suited to examining the effects of inflation-taxation interactions. Elsewhere I have argued that, in any realistic model in which tax effects are the principal source of non-

52. Feldstein and Summers, "Inflation, Tax Rules, and the Long-Term Interest Rate."

53. See, for example, Martin Feldstein, "Inflation, Tax Rules, and the Stock Market," Journal of Monetary Economics, vol. 6 (July 1980), pp. 309-31; Hendershott, "The Decline in Aggregate Share Values," and Roger Gordon, "Inflation Taxation and Corporate Behavior," Working Paper 588 (National Bureau of Economic Research, December 1980). 
neutrality, interest rates should rise much more than point for point with the rate of inflation. ${ }^{54}$ The failure of interest rates to respond in this way to inflation historically suggests that other nontax factors have been in operation. If the goal is to examine the interactions between inflation and taxes, these factors should be excluded from consideration and a greater than point-for-point adjustment of interest rates to inflation should be assumed. If this were done, inflation would have a larger negative impact on capital formation than is suggested by the simulations above. ${ }^{55}$

Alternatively, if the goal is to explain the historical experience, one must consider the possibility that the nontax factors affecting the relation between interest rates and inflation also influence the relation between inflation and the required return on equity. Throughout the post-World War II period, increases in inflation have been associated with increased variance in real economic performance and volatility in stock prices. Although there is no evidence of causality in this correlation, a positive correlation between inflation and the equity risk premium is also likely. This would account for the decline in real after-tax bond yields, but would imply that the inflation has been associated with increases in the required return on equity. This prediction is borne out by the high ratios of earnings to prices that have prevailed throughout the 1970s. The apparent increases in risk premiums may also be the result of inflation illusioninvestors equate required real returns on equity with nominal bond yields. ${ }^{56}$

The argument presented above, that inflation has not depressed the required return on equity, is supported by the recent analysis of Brainard, Shoven, and Weiss. ${ }^{57}$ The internal rate-of-return series that they calculate can be interpreted as estimates of the rate of return required by corporate investors. While their series excludes individual tax effects and includes

54. This discussion draws on Lawrence H. Summers, "The Non-Adjustment of Nominal Interest Rates: A Study of the Fisher Effect," National Bureau of Economic Research, Conference Paper, forthcoming.

55. This is because the net gains firms realize due to the combination of higher interest rates, nominal interest deductibility, and capital gains on debt would be less than those in the simulations reported here.

56. For a forceful argument that this has in fact occurred, see Modigliani and Cohn, "Inflation and Rational Market Valuation." A major difficulty with the Modigliani-Cohn view is that a similar inflation illusion has not plagued the housing market. This is surprising because participants are financially less sophisticated and more constrained by liquidity than investors in the stock market.

57. William C. Brainard, John B. Shoven, and Laurence Weiss, "The Financial Valuation of the Return to Capital," BPEA, 2:1980, pp. 453-502. 
both debt and equity, it shows a strong positive correlation with inflation. As the authors emphasize, it is hard to explain a priori why required rates of return should have risen so much in recent years. However, in modeling the effect of recent inflation, it is conservative to assume that the required rate of return on equity has remained constant.

A fully satisfactory treatment of tax effect on the required rate of return must await the development of a general equilibrium model with several types of capital in which savings are determined by intertemporal optimization. This is an important area for future research.

\section{Conclusions}

It is generally accepted that incentives to spur investment in plant and equipment should be designed to maximize the additional investment generated per dollar of forgone revenue. Another appropriate objective is to minimize windfall gains and losses to owners of existing capital. Alternative tax measures to spur the same amount of investment are likely to have very different effects on revenue and equity. The design and not just the size of increases in investment stimulus are thus important issues.

One lesson that emerges is the desirability of focusing incentives on investment in plant and equipment rather than on saving in general. As emphasized in the preceding section, because the supply of funds to the corporate sector is highly elastic, only a fraction of any increase in national saving would find its way into corporate capital. Much would be channeled into housing and into bidding up the price of inelastically supplied assets such as land. This argument applies equally to increases in saving achieved through tax incentives for savers and other measures such as larger government surpluses.

The results suggest that the most desirable investment incentives are those that operate by reducing the effective purchase price of new capital goods. They maximize the investment "bang for the buck" and minimize the windfall to corporate shareholders upon enactment. Particularly to be avoided, according to the model, are reductions in dividend taxes. Their only permanent effect is to provide a windfall to existing corporate shareholders. The increase in the after-tax return to shareholders from reductions in the dividend tax is exactly offset by the increased after-tax cost of retaining earnings. Reducing corporate tax rates has effects in between these extremes. 
Consideration of interactions between tax policy and inflation is essential to policymaking. Inflation raises the effective taxation of corporate capital, causes large losses to corporate shareholders, and reduces the rate of capital accumulation. As long as the tax system is not indexed, distortions will be caused by inflation, even if it is anticipated and involves no relative price changes. Another lesson of this paper is the importance of the announcement and timing effects of tax changes. While increases in the investment tax credit or accelerated depreciation stimulate investment, the effects of those increases will depend critically on the timing of announcement and enactment. An even more dramatic example of the importance of timing is provided by the corporate tax rate. Because of accelerated depreciation, an announced but not yet implemented permanent tax cut will have a larger impact on investment than will a permanent cut that has already been made. Appropriate policy announcements can thus increase investment without substantial revenue costs. By combining policies, it is possible to spur investment without revenue cost or windfalls.

\section{APPENDIX A}

\section{The Derivation of $Q$}

This APPENDIX draws on earlier work by others, especially Fumio Hayashi, to show that under certain circumstances there is an exact correspondence between average $q$ as measured in the conventional way and the shadow price of capital or "marginal" $q$ associated with dynamic optimization of a firm's value in the presence of adjustment costs. ${ }^{58}$ The link between average and marginal $q$ requires certain adjustments for tax effects, as is described in the text. Once these adjustments are made, it is shown that an econometric investment equation can be used to estimate the aggregate adjustment-cost function. This provides the basis for the estimates of the effects of tax policy reported in the paper.

58. Fumio Hayashi, "Tobin's Marginal $q$ and Average $q$ : A Neoclassical Interpretation," Discussion Paper (Center for Mathematical Studies in Economics and Management Science, Northwestern University, March 1981), forthcoming in Econometrica. 
I begin by examining how individuals value corporate stock and then turn to the decision problem facing a firm. Throughout it is assumed that a firm neither issues new equity nor repurchases existing shares. ${ }^{59}$ Hence share prices are proportional to the outstanding value of a firm's equity. It is also assumed that equity holders require a fixed real after-tax return, $\rho$, in order to induce them to hold the outstanding equity. It is assumed that the value of $\rho$ is not affected by either changes in tax rules or the quantity of equity. The required return, $\rho$, is the sum of capital gains and dividends net of tax. It follows that

$$
(\rho+\pi) V_{t}=(1-c) \dot{V}_{t}+(1-\theta) D i v_{t_{1}}
$$

where $c$ is the capital gains tax rate on an accrual basis and $\theta$ is the dividend tax rate. ${ }^{60}$ All investors are assumed to have the same tax rates. ${ }^{61}$ This differential equation can be solved to find the time path of $V$. In order to ensure a unique solution, it is necessary to impose a condition that rules out explosive behavior. The transversality condition that guarantees a unique solution to $\mathrm{A}-1$ is

$$
\lim _{s \rightarrow \infty} V_{s}\left(\exp \int_{t}^{s} \frac{-(\rho+\pi)}{(1-c)} d u\right)=0 .
$$

With this condition satisfied and the assumption of perfect foresight about future dividends, the solution to A-1 becomes

$$
V_{t}=\int_{t}^{\infty} \frac{(1-\theta)}{(1-c)} \operatorname{Div}_{s}\left(\exp \int_{t}^{s} \frac{-(\rho+\pi)}{(1-c)} d u\right) d s .
$$

Each firm is assumed to produce with constant returns to scale and to be perfectly competitive in all markets, taking as given the price of its output, the wage, and the rate of return required by investors. These competitive assumptions, together with the requirement that capital is homogeneous,

59. Under the conditions described below, a firm would never want to issue new equity. Legal restrictions severely limit the firm's ability to repurchase its own shares as a device for avoiding dividend taxation. For a discussion of these restrictions and the limitations of other mechanisms that might seem to be functionally equivalent to repurchasing shares, see Alan J. Auerbach, "Wealth Maximization and the Cost of Capital," Quarterly Journal of Economics, vol. 93 (August 1979), pp. 433-46.

60. The capital gains tax rate corresponds to the statutory rate adjusted for deferral and the lack of constructive realization at death. An additional complication is introduced by the absence of full-loss offset provisions in the tax code.

61. Feldstein shows an approach to handling the case of heterogeneous investors. See his "Tax Rules." 
are essential to the derivation of the linkage between market valuation and investment incentives that is discussed below.

The typical firm seeks to choose an investment and financial policy to maximize A-3 subject to the constraints given by its initial capital stock, by a requirement that the sources of funds equal the uses, and the requirement, discussed in the text, that the firm maintains debt equal to a fixed fraction, $b$, of the capital stock.

A crucial feature of the model is that there is a cost to changing the capital stock. Without this cost, the size of the firm would be indeterminate because of the constant returns to scale and the assumption of perfect competition. The cost of installing additional capital rises with rate of capital accumulation, thereby preventing jumps in the demand for capital. The cost function is taken to be convex and homogeneous in investment and capital. Under these conditions, dividends can be derived as after-tax profits minus investment expenses. ${ }^{62}$ Thus,

$$
\begin{aligned}
\operatorname{Div}=[p F(K, L) & -w L-p b i K](1-\tau) \\
& -(1-I T C-b+(1-\tau) \phi) p I \\
& +\tau D+p b K\left(\pi-\delta^{R}\right),
\end{aligned}
$$

where

$$
\begin{aligned}
K \text { and } L & =\text { factor inputs } \\
p & =\text { overall price level } \\
F(K, L) & =\text { production function } \\
w & =\text { wage rate } \\
i & =\text { the nominal interest rate } \\
\tau & =\text { corporate tax rate } \\
I T C & =\text { investment tax credit } \\
\phi & =\text { adjustment-cost function, assumed to be convex } \\
I & =\text { investment } \\
\delta^{R} & =\text { rate of economic depreciation of the capital stock } \\
D & =\text { value of currently allowable depreciation allowances. }
\end{aligned}
$$

The calculation of $D$ assumes that the rate of depreciation used for tax

62. The assumption here is that all marginal equity finance comes from retained earnings. This follows from the assumption of a constant number of shares made earlier. It accounts for some of the apparently paradoxical results described below. The last term reflects the net receipts from issuance of new debt (withdrawals) necessary to maintain the ratio of debt to capital as the capital stock depreciates and the price level rises. 
purposes reflects accelerated depreciation and that tax depreciation is based on historical cost. Adjustment costs are considered expensed and ineligible for the investment tax credit. If these costs are taken to represent managerial effort, or interference with concurrent production, the assumption made here is appropriate. Treating adjustment expenses as investment under the tax law would not importantly alter the results.

Combining equations A-3 and A-4 and separating the terms reflecting the value of depreciation allowances on existing capital, $B$, and future acquisitions, $Z$, yields an expression for the market value of a firm's equity at time $t$ :

$$
\begin{aligned}
\text { (A-5) } V_{t}= & \int_{t}^{\infty}((p F(K, L)-w L-p b K i)(1-\tau)-(1-I T C-Z-b \\
& \left.+(1-\tau) \phi) p I+p b K\left(\pi-\delta^{R}\right)\right) \frac{(1-\theta)}{(1-c)} \mu_{s} d s+B_{t} .
\end{aligned}
$$

All the tax parameters can be arbitrary functions of time. For the purpose of exposition the following symbols are introduced:

$$
\mu_{s}=\exp \int_{t}^{s}-\frac{(\rho+\pi)}{(1-c)} d u
$$

$$
B_{t}=\int_{t}^{\infty} \tau_{s} \delta^{T} \mu_{s} \frac{(1-\theta)}{(1-c)} K D E P_{t}\left[\exp \left(-\delta^{T}\right)(s-t)\right] d s
$$

$$
Z_{s}=\int_{s}^{\infty} \tau \delta^{T} \frac{\mu_{u}}{\mu_{s}}\left[\exp \left(-\delta^{T}\right)(u-s)\right] d u .
$$

The $B_{t}$ variable represents the present value of depreciation allowances on existing capital; ${ }^{63}$ the $Z_{s}$ is the present value, evaluated at time $s$ of the depreciation allowances, on a dollar of new investment.

In maximizing equation A-5, the firm can ignore $B_{t}$ because it is independent of any current or future decisions. The constraint that capital accumulation equals net investment faced by the firm in maximizing A-5 is

$$
\dot{K}_{s}=I_{s}-\delta^{R} K_{s}
$$

This dynamic optimization problem can be solved using the Pontryagin maximum principle. A shadow price, $\lambda(t)$, is introduced for the con-

63. The $K D E P_{t}$ refers to the depreciable capital stock at time $t$. It differs from $K_{t}$ because of historical cost and accelerated depreciation. 
straint given by A-7. It can be interpreted as marginal $q$, the change in a firm's value resulting from a unit increment to the capital stock. The firstorder conditions for optimality are ${ }^{64}$

$$
\begin{aligned}
& \text { (A-8a) } \quad F_{L}=\frac{w}{p} \\
& \begin{array}{c}
\text { (A-8b) } 1-I T C-Z-b+\phi(1-\tau)+\frac{I}{K} \phi^{\prime}(1-\tau)=\frac{\lambda(1-c)}{p(1-\theta)} \\
\text { (A-8c) } \dot{\lambda}=\lambda\left(\frac{(\rho+\pi)}{(1-c)}+\delta^{R}\right)-\left(\left(p F_{K}-b i\right)(1-\tau)-p\left(\frac{I}{K}\right)^{2}(1-\tau) \phi^{\prime}\right. \\
\left.+b\left(\pi-\delta^{R}\right)\right) \frac{(1-\theta)}{(1-c)} .
\end{array}
\end{aligned}
$$

The first-order condition, equation A-8a, implies that labor is hired until its marginal product and wage are equal. Equation A- $8 \mathrm{~b}$ characterizes the investment function; it implicitly defines a function linking investment to the real shadow price of capital, $\lambda / p$, the tax parameters, and the costs of adjustment. This equation has an intuitive explanation. The righthand side is the shadow price of additional capital goods, which is equal to their marginal cost in after-tax corporate dollars on the left-hand side. The condition for zero investment is

$$
\frac{\lambda}{p}=\frac{(1-\theta)}{(1-c)}[1-I T C-Z-b] .
$$

Equation A-9 implies that there will be investment even if the shadow price of new capital goods is less than 1 . This is because taxes and debt finance reduce the effective price of new capital goods. The third firstorder condition, A-8c, describes the evolution of the shadow price, $\lambda$. It guarantees that the shadow price equals the present value of the future marginal products of a unit of capital. In this model, capital investment is productive in terms of output and, because of the form of the adjustment-cost function, in reducing the cost of subsequent investment.

Equation $\mathrm{A}-8 \mathrm{~b}$ is of no operational significance as a theory of investment unless an observable counterpart to the shadow price, $\lambda / p$, can be obtained. Hayashi has shown in a similar model with a less elaborate tax

64. Similar first-order conditions with different assumptions about tax effects can be found in Abel, "Empirical Investment Equations," and Hayashi, "Tobin's Marginal $q$ and Average $q . "$ 
system how the shadow price is linked to the market valuation of existing capital. ${ }^{65}$

This link can be demonstrated as follows. Note that $V_{t}-B_{t}$ given by equation A-5 is homogeneous in $K_{t}$-that is, a doubling of $K_{t}$ together with the optimal doubling of investment and labor in every subsequent period will double $V_{t}-B_{t}$. This is a consequence of the constant-returnsto-scale production function and the homogeneity of the adjustment-cost function. It follows directly that

$$
V_{t}^{*}-B_{t}=\gamma p_{t} K_{t},
$$

where $V_{t}^{*}$ is the stock market's value at time $t$ when the optimal path is followed. In other words, the maximized value of the firm at time $t$ minus the value of depreciation allowances on existing capital is proportional to the value of its initial capital stock. The maximum principle implies that

$$
\frac{d V_{t}^{*}}{d K_{t}}=\lambda_{t}
$$

This is what is meant by the assertion that $\lambda$ is the shadow price of new investment, or marginal $q$. Combining equations A-10 and A-11 demonstrates that

$$
\lambda_{t}=\frac{V_{t}^{*}-B_{t}}{p_{t} K_{t}}
$$

This expression provides an observable counterpart for the shadow price of new investment if it is assumed that the firm maximizes value so that $V_{t}=V_{t}^{*}$. It implies that the investment function can be written

$$
\frac{I}{K}=h\left(\frac{\frac{(V-B)(1-c)}{p K(1-\theta)}-1+b+I T C+Z}{1-\tau}\right)=h(Q),
$$

where $Q$ is the tax-adjusted $q$ and $h(\cdot)=\left(\phi+(I / K) \phi^{\prime}\right)^{-1}$.

For convenience, it is assumed that adjustment costs per unit of capital are zero up to some normal level of investment, and then rise linearly with investment above that level. In particular, total adjustment costs for

65. Hayashi, "Tobin's Marginal $q$ and Average $q$." For a more rigorous proof than the heuristic argument given here, see M. Salinger and L. Summers, "Tax Reform and Corporate Investment: A Microeconometric Simulation Study," in Martin Feldstein, ed., Tax Simulation Analysis, forthcoming. 
a level of investment, $I$, are given by

$$
\begin{aligned}
& A=\frac{\beta}{2}\left(\frac{I}{K}-\gamma\right)^{2} K \quad \text { if } \quad\left(\frac{I}{K}-\gamma\right) \geq 0 \\
& A=0 \quad \text { if } \quad\left(\frac{I}{K}-\gamma\right)<0 .
\end{aligned}
$$

It follows that the function $\phi(\cdot)$ is given by

$$
\phi\left(\frac{I}{K}\right)=\frac{\frac{\beta}{2}\left(\begin{array}{l}
I \\
K
\end{array}\right)^{2}}{\frac{I}{K}}
$$

which is homogeneous in $I / K$ as required.

This implies that the investment function, A-13, can be written as

$$
\frac{I}{K}=h^{-1}(Q)=\gamma+\frac{1}{\beta} Q
$$

where $Q$ represents tax-adjusted Tobin's $q$. This is the linear relation between investment and $Q$ that is estimated in the text.

\section{APPENDIX B}

\section{Description of the Components of $Q$ in Equation 11}

\section{Description}

$V \quad$ The stock market value of all nonfinancial corporations at the beginning of the year is estimated by capitalizing nonfinancial corporate dividends using the Standard and Poor's dividend yield. For 1947-78, fourth-quarter dividends from the previous year are capitalized using the average fourth-quarter dividend price ratio for the preceding year.

$K \quad$ The capital stock, $K$, at the beginning of the year is taken to be the sum of equipment, structures, and inventories, all valued at current replacement cost. 
The present value of depreciation allowances is estimated in several stages. First, the value of the depreciable capital stock is calculated using the perpetual inventory method and annual data on investment and tax depreciation. Second, the tax depreciation rate is estimated as the ratio of tax depreciation to depreciable capital stock. Third, $B$ is calculated from equation A-6b, using the current corporate tax rate and the corporate bond rate as the discount rate. This discount rate was chosen because the stream of future depreciation allowances, unlike the stream of future profits, is close to being risk free in nominal terms.

$b \quad$ The ratio of the market value of outstanding corporate debt, less financial assets, to the capital stock, $K_{t}$, is a proxy for the value of $b$. While the analysis above justifies the use of this proxy only in the case in which all debt is short term, it is approximately valid for the case of long-term debt. ${ }^{66}$ The market value of debt is estimated by capitalizing net interest payments at the Baa corporate bonds rate. ${ }^{67}$

c It is difficult to measure the effective tax rate on capital gains because of the problems inherent in estimating the effects of deferral and the absence of constructive realization at death. Following Bailey it is assumed that each of these factors divides the effective rate in half. From 1932 to 1969 , the statutory rate on capital gains was half the rate on dividends. ${ }^{68}$ Hence for this period the capital gains rate was estimated at 12.5 percent of the average marginal dividend tax rate. ${ }^{69}$ For the 1969-78 period, this rate is assumed to be 50 percent

66. This follows because exactly offsetting adjustment must be made to $b$ for capital gains or losses realized by firms on outstanding debt. In a taxless world, this treatment leads to Tobin's $q$ variable as defined for bonds plus equity.

67. This procedure would be strictly appropriate only if all bonds were consols. Comparing the results with those of von Furstenberg, "Corporate Investment," suggests that the error is not likely to be large.

68. Martin J. Bailey, "Capital Gains and Income Taxation," in Arnold C. Harberger and Martin J. Bailey, eds., The Taxation of Income from Capital (Brookings Institution, 1969), pp. 11-49.

69. The construction of this series is discussed below. 
higher, or 18.75 percent of the dividend rate, reflecting the effect of the 1969 capital gains reforms. ${ }^{70}$

$\theta \quad$ The marginal tax rate on dividends is estimated as a weighted average of individual marginal rates with weights equal to the share of dividends to taxpayers in each marginal rate class. ${ }^{71}$ Because of data limitations, equity owned outside the household sector is not included.

ITC The effective rate of the investment tax credit is the statutory rate, as adjusted by Data Resources, Incorporated, to reflect the effects of eligibility rules, multiplied by the sample average share of investment devoted to equipment.

$Z \quad$ The present value of future depreciation allowances on a dollar of investment is calculated on the basis of tax lifetime and depreciation methods actually used as estimated by Data Resources, Incorporated. Static expectations about future corporate tax rates are assumed. A fixed-weight average of the figures for equipment and structure is used.

$\tau \quad$ The corporate tax rate is the statutory marginal tax rate on corporate income. ${ }^{72}$

70. These reforms included the minimum tax, maximum tax, and special provisions relating to preference income. The suggestion that these reforms raised effective rates by about 50 percent is derived from the TAXSIM model of the National Bureau of Economic Research.

71. A zero marginal tax rate is assigned to dividends sheltered in the Keogh plans and similar plans. The series are taken with adjustment from Colin Wright, "Saving and the Rate of Interest," in Harberger and Bailey, eds., The Taxation of Income From Capital, pp. 275-300 and Roger E. Brinner and Stephen H. Brooks, "Stock Prices," in Henry J. Aaron and Joseph A. Pechman, eds., How Taxes Affect Economic Behavior (Brookings Institution, 1981), pp. 199-240.

72. This series is taken from John J. Seater, "Marginal Federal Personal and Corporate Income Tax Rates in the U.S., 1909-1975," Research Paper 57 (Federal Reserve Bank of Philadelphia, November 1980). 


\section{Comments and Discussion}

Barry P. Bosworth: Larry Summers has provided a useful and interesting contribution to the exploding literature on the effect of tax policy on capital formation. The first part of the paper reports on some extensions of the neoclassical model of investment demand in three areas. These include a more elaborate treatment of taxation, the use of stock market values as a source of information on investors' perceptions of the profitability of investment, and the linkage between investment (a flow concept) and changes in the demand for capital (a stock concept).

The formulation of an empirically testable version of the neoclassical investment model, inclusive of taxation, derives from the work of Haavelmo, Jorgenson, Hall, and others in the 1960s. That formulation assumed that the after-tax required return faced by the firm was constant, and it dealt only with corporate taxes. By assuming a fixed after-tax return, the model forced tax changes to rebound forward onto the price of investment rather than backward on the return to savings. The assumption, together with the specification of a Cobb-Douglas production function (with the potential for substantial substitution between capital and labor inputs), accentuated the effect of taxes on investment.

This paper goes a step further in assuming that corporate managers act to maximize the after-tax position of their shareholders. Thus it incorporates the personal income tax on dividends and capital gains into the analysis. It also assumes that the after-tax real rate of return required by savers is fixed. This latter assumption is particularly crucial because it implies that the elasticity of the supply of funds for corporate investment is infinite and that all tax changes will rebound forward onto changes in the price of investment. The analysis thus provides an upper bound on the potential effects of tax policy on investment demand. 
By integrating personal taxes into the analysis, Summers has merged two areas of economic analysis, production theory and valuation theory, into one. In more traditional analysis, valuation theory enters the discussion of the determinant of the cost of capital to the firm and the choice between debt and equity finance.

In undertaking this merger, Summers makes several very restrictive assumptions. First, the firm can neither issue nor retire stock. Second, the amount of external debt is rigidly tied to the replacement value of the capital stock. There is, therefore, no decision on the financing side-investment requires the reduction of dividends; that is, production and financing decisions become one and the same. Summers cites Auerbach as justification for the view that stock issues are unimportant. Perhaps this is a judgment issue but I would note that such issues have varied annually from 1 to 13 percent of capital investment over the last decade and represent a much larger share of external financing. Similarly, data supplied by von Furstenberg does not imply that the ratio of debt to capital is a constant.

The abnormalities introduced by this assumption are most evident in the analysis, which suggests that announcement of a future rise in dividend taxes will reduce investment before it takes place and will raise it afterward. To transfer income to stockholders at the temporary low tax rate, firms must cut investment. In the more traditional valuation framework a firm would borrow money to prepay dividends without the need to disrupt its investment plans.

A more interesting example of the role of the assumptions is provided by the statement that the dividend tax rate has no influence on the capital stock in a long-run steady-state. That would appear to make the reduction of the highest income tax rates a pure windfall. Because investment must be financed by reducing dividends, the cost to the investor is $(1-\theta)$, where $\theta$ is the tax rate. Later, when the return on investment raises dividends, they are taxed at $(1-\theta)$. So when costs and returns are equated, the dividend-tax rate cancels from both sides of the expression. A permanent tax increase reduces the cost of investment by the same amount that it reduces future receipts. Even at a 100 percent tax rate the fact that the investor gains nothing is offset by the fact that investment costs nothing. In the steady state the income from capital is just adequate to maintain its growth. Capital gains cannot provide financing for investment nor a substitute for dividends. These conclusions, however, are a product of the 
restrictive assumptions and vanish in a model with more than one source of financing. In the more general case, the tax on dividends is part of the taxation of capital income and will affect the desired capital stock.

The conclusion that dividend taxes do not affect investment in this model is not surprising because it is the same result that is obtained for the independence of the capital stock and the corporate tax rate when investment is expensed in the period in which it is made. This does not imply the absence of taxes, only that they are not paid at the margin. In other words, an oil company pays taxes, but the corporate tax does not affect its decision on how many exploratory wells to drill. In the same sense, there continues to be a dividend tax in Summers' world, even though the equivalence of dividends and investment at the margin implies that it does not affect the steady-state capital stock. The conclusions about the corporate tax, however, are much more robust with respect to the assumptions than his conclusions for the dividend tax.

The second major contribution is in the amendment of Tobin's $q$ concept for taxes in a way that parallels the formulation of the rental price by Jorgenson and others. The analysis draws heavily from a paper by Hayashi that gives such an adjustment for corporate taxes. Because the purpose of using market valuation data in investment equations is to determine if useful information is provided on investor perceptions of opportunities, the failure in several past studies to adjust for changes in dividend and capital gains taxes is a significant omission. Summers is most struck by the secular decline in the unadjusted $q$ ratio (the ratio of the firm's market value to its capital stock). I am most struck by the tremendous variability in the adjusted measure, $Q$. Looking at the terms that make up the adjustment, I am puzzled about the source of the variability; it does not appear to be accounted for by any of the tax components Summers reports, so presumably it reflects variations in $q$.

One difficulty with the use of stock market valuation to infer investor perception of physical investment opportunities is that the information must be taken in toto. But the information relevant to investment may be overshadowed by the volatility of the "noise" in stock market fluctuations. For example, a high $q$ in 1929 should not have implied that businessmen should buy more $K$; rather, they should sell more $V$. In this respect, it seems inappropriate to use an extremely weak empirical correlation between the stock market and investment to infer tax policy effects on investment - particularly when derivation of the impact of tax policy 
on stock prices is greatly dependent upon the valuation theory adopted. A second difficulty is that the argument Hayashi and Summers make for a stable relation between average and marginal $q$ does not deal with the problem of capital obsolescence that Baily's paper in this issue stresses.

Third, much of the existing theoretical literature is directed toward defining the determinants of the desired capital stock, while the process of investment as a transition from one stock to another is given short shrift. Summers argues that this model solves that difficulty by incorporating an explicit adjustment function by which costs rise with the rate of investment. That is true, but it is still ad hoc in nature and is little different in its implication from the models of Lucas, Gould, Treadway, and others who made similar assumptions within the standard neoclassical model. The nature of those costs is still unknown, and to assert that the costs of investment rise with the level of investment is to assume away the question of whether or not a marginal efficiency of investment schedule exists at the micro level.

From my own perspective, the major feature of investment in practice that continues to be ignored in theory is its irreversibility. There is not a full resale market for capital, and models that assume myopic decisionmaking miss the fixed-cost characteristic of capital that is such a dominant feature of the micro analysis. Such models pass relatively quickly over the first-order issue of expected future utilization of new capital and place relatively heavy stress on the second-order issue of the optimal degree of capital intensity. Thus there has always been a contrast between the empirical models that find a dominant role for output expectations (a scale factor) and the theoretical models that place equal stress on relative prices (factor intensity).

Finally, Summers cites one of his previous papers on saving in a lifecycle model in support of a view that interest rates have a larger positive effect on saving than previously believed. That paper reaches such a conclusion because a rise in interest rates reduces the present value of future labor income, thus reducing the individual's current consumption. But the paper ignores the role of wealth that exists at the time the change in interest rate occurs. The effect on people who hold substantial wealth at the time of the change in the interest rate is ambiguous. Those holding short-term assets will experience a substantial rise in future after-tax income and thus increase their consumption. I do not believe the paper resolved the empirical issue of the interest elasticity of saving, but it did 
highlight, in my mind, that the effect of interest rates on saving will depend on the ratio of initial current wealth to future labor income. Thus short-term aggregate analysis may provide misleading empirical analysis because of the mixture of individuals in different financial situations. From this perspective, tax measures are likely to be more effective in increasing saving if they are focused on individuals who have not yet accumulated significant wealth.

Despite my reservations about the model and the ambiguity of the empirical findings, the policy simulation produces empirical results that are not violently different from those obtained with more conventional neoclassical models such as that of Jorgenson. The Jorgenson model, with today's tax laws, implies that an 8 percent inflation rate would reduce the desired capital stock by about 20 percent. Because Summers includes personal as well as corporate taxes, his estimate of 28 percent may be consistent with estimates from conventional models. But again, the methodology is designed to maximize the estimated impact of taxes on investment. It does not directly address continuing disagreements among economists about the magnitude of the critical parameters. An observation of a positive but weak correlation between investment and the stock market, for example, does not resolve the empirical debate over the magnitude of the elasticity of factor substitution between capital and labor any more than Jorgenson's assertion that the world was Cobb-Douglas satisfied Robert Eisner.

James Tobin and Philip M. White: One explanation offered for the observed decline in real stock prices and in $q$ in the 1970s is the interaction of higher inflation with nonneutral taxes. This has also been put forth as an explanation for the alleged poor performance of nonresidential capital investment during the same period.

Larry Summers' paper examines both hypotheses and shows how they are connected. However, in his introductory empirical review he finds that, partly because of the recent revision of the national income account, the performance of corporate fixed investment was not as much of a problem as previously perceived. He also found in reviewing tax legislation changes during the 1970s that reductions in the taxation of equity income have compensated in part for some of the distortions introduced by inflation.

Gross investment as a proportion of GNP was high during the past 
decade relative to earlier postwar years. This was not true of net investment as estimated by the Department of Commerce. A shift toward equipment away from structures, together with a rise in the capital-output ratio, led to higher replacement investment. Inflation in its interaction with historical cost depreciation is one reason for the shift toward shorter-lived capital goods but other factors might have contributed. For one, the relative price of structures vis-à-vis equipment has increased. According to the revised national product accounts, the 1979 GNP deflator for structures was twice its 1972 level while the equipment deflator had risen only 60 percent. The investment tax credit also favors short-lived capital; every time it is replaced the investor receives both the credit and full depreciation.

The inflation-tax story is not the only explanation for the shortfall of investment, to the extent that there was one, and for the performance of the stock market. Other observers have pointed to the recessions and excess capacity that characterized much of the decade, to oil and energy shocks, and to greater macroeconomic risks perceived by business and the general public because of stagflation and the expected side effects of antiinflationary policies.

The model Larry Summers has constructed to explore these issues is impressive and ingenious. It has several noteworthy features. One important innovation is that firms in Summers' economy incorporate the tax position of their shareholders. In effect, firms invest up to the point at which the cost of investment in terms of after-tax dividends equals the increase in the firms' value after capital gains taxes. Valuation in the model is the present value of dividends given a perfect foresight path of wages, interest rates, inflation, and tax policy. Thus there are no systematic prediction errors and, as Lucas wants us all to make sure, no fivehundred-dollar bills on the sidewalk.

The incorporation of taxes in both valuation and investment strategy is important in interpreting movements of $q$ and investment when tax parameters change. As Summers points out, conventional $q$ and investment could theoretically move in opposite directions. A cut in taxes on capital income could spur investment to the point that the increase in the capital stock so increases future real wages that all the benefit from the tax cut flows to labor.

Firms in the model never issue or retire any equity. It is this assumption that is responsible for the strong result that the dividend tax rate does not 
affect investment in the steady state. In effect, a cut in dividend taxes increases in proportion the opportunity cost of current investment in terms of after-tax dividends and the benefit in capital gains.

Although firms optimize retained earnings relative to dividends, they maintain a constant ratio of debt to replacement cost of capital. In this respect they are not completely rational. The debt-to-equity ratio, even if it had been chosen optimally at zero inflation, would not remain the same at higher inflation rates. It would be higher because the tax deductibility of nominal debt interest payments would be more valuable.

An adjustment cost theory explains the level of investment. In the simulations, which use an estimated adjustment cost function, these costs are substantial. In the steady state, the average cost of adjustment is 22 percent of the price of a machine, and the marginal cost of adjustment is approximately 1.94 times the commodity cost of capital. This means that adjustment costs raise the total resource cost for that marginal machine from 1 to nearly 3 . That is a lot!

Summers estimates adjustment costs by inverting empirical regressions of investment on his tax-adjusted $q$ series. There is great merit in the adjustment cost story, but maybe it need not be taken so literally and exclusively. Despite the parable of the five-hundred-dollar bills mentioned above, one should not exclude the possibility that it simply takes time for firms to respond to incentives and that the distributed lag regression of investment on $q$ reflects disequilibrium.

Aggregation is another explanation for why inverting the investment equation exaggerates adjustment costs. The observed aggregates conceal a dispersion of $q$-values and investment rates across firms. Movements of the aggregates reflect nonlinear responses by low- $q$ and high- $q$ firms.

Summers enumerates four sources of nonneutrality in the tax system. These are the deductibility of nominal interest payments, historical cost depreciation, FIFO inventory accounting, and the taxation of nominal capital gains.

One general point, which perhaps everyone knows but sometimes appears to have forgotten, is that there is a basic nonlinearity in the tax loss due to historical cost depreciation whereas the gain from interest deductibility is linear in inflation. Figures 1 and 2 below illustrate this point. On the horizontal axis is inflation and on the vertical axis is the required rate of return which for a given steady state of real investment keeps $q$ equal to 1 (or Summers' $Q$ equal to zero). In figure 1 only the effect of 
Figure 1. Nonlinear Effect of Inflation on Internal Rate of Return $(A D)$, Depreciation Tax Loss Only

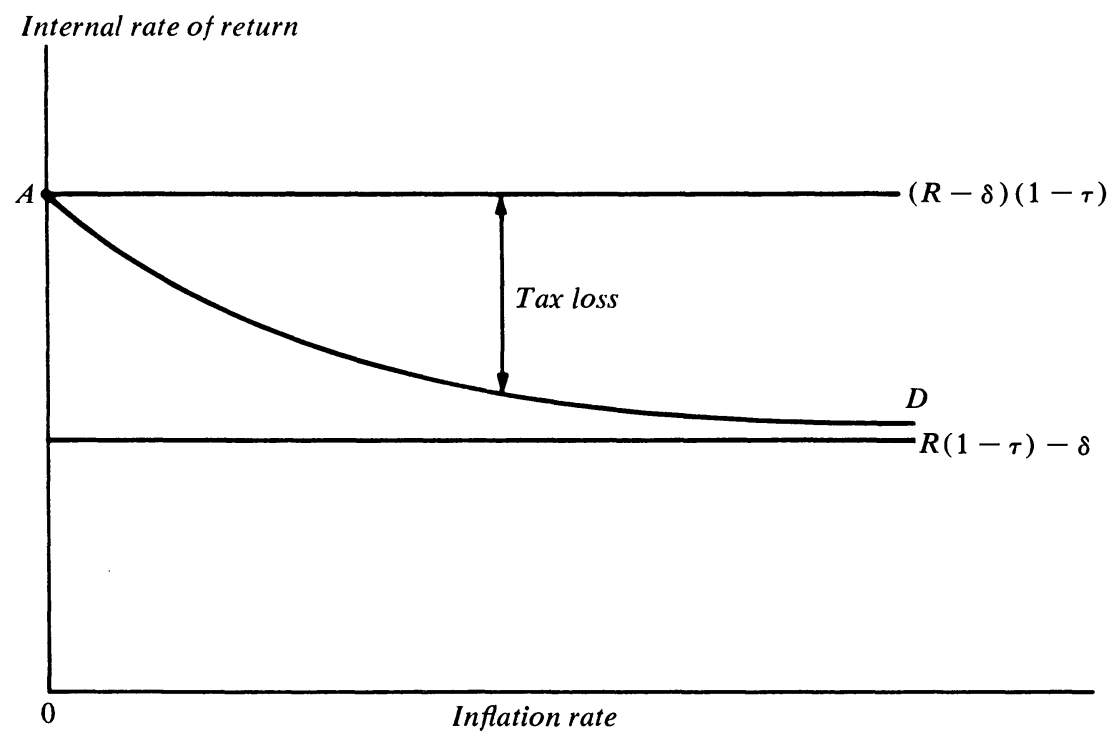

Notes: The symbol $R$ is the gross real before-tax rate of return; $\delta$ is the depreciation rate; and $\tau$ is the tax rate.

historical cost depreciation is plotted. Along $A D$ the internal rate of return decreases with inflation but is asymptotic to a lower limit. No matter how high inflation is, the most the firm can lose is the value of this depreciation tax deduction. For example, if the depreciation rate is 8 percent and the tax rate is 50 percent, the maximum loss of rate of return due to historical cost accounting is 4 percentage points.

If the firm borrows enough to maintain its debt at a constant fraction of the replacement cost of its capital stock and the nominal interest rate rises point for point with inflation, the benefit of the deductibility of interest payments is the tax rate times the ratio of debt to replacement cost times the rate of inflation. This is linear in inflation and plotted as curve $A F$ in figure 2. Subtracting the loss due to depreciation from $A F$ gives a curve like $A B C D$. At point $B$ inflation has done its worst and beyond points like $C$ the gain from the interest deductibility exceeds the depreciation loss.

For the values in Summers' paper, the point $B$ occurs at 9 percent inflation. Thus if the only nonneutralities were historical cost depreciation and 
Figure 2. Effect of Inflation on Internal Rate of Return ( $A B C D$ ), Depreciation Tax Loss and Interest Deductibility Gain

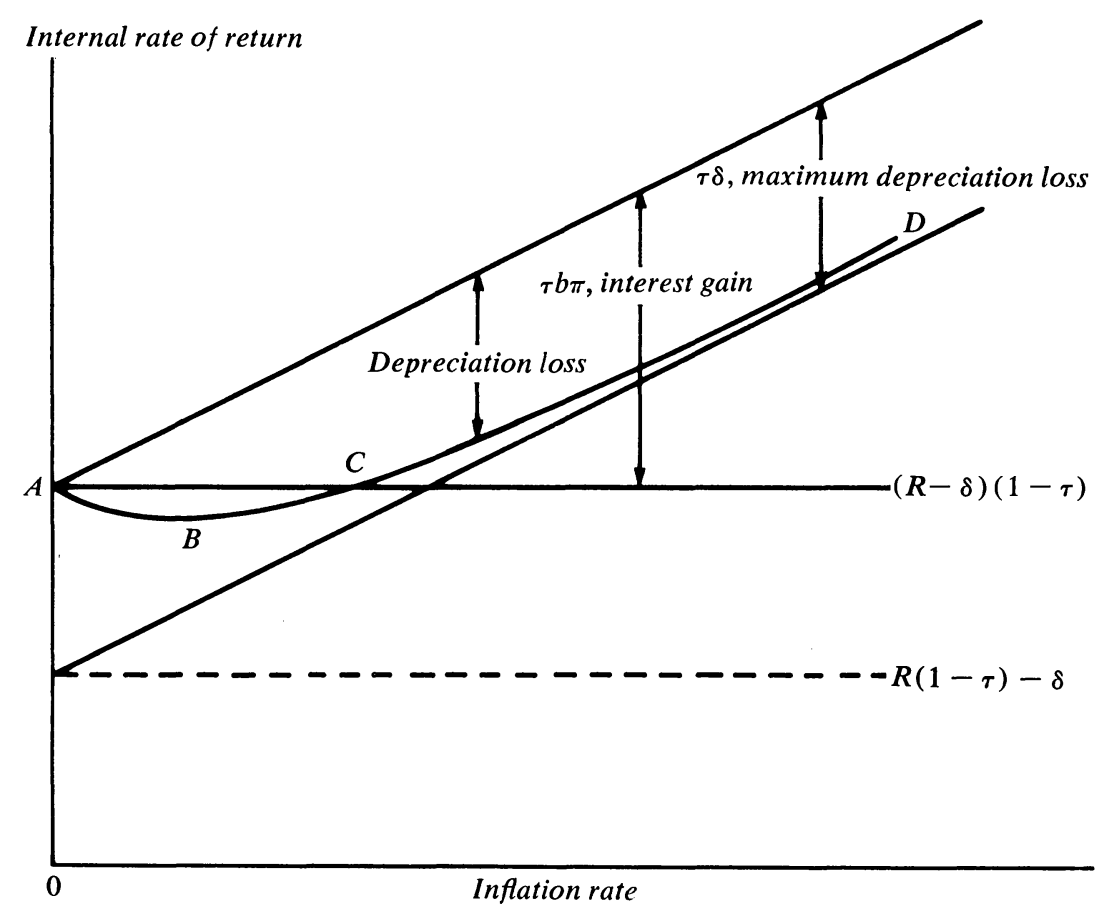

Notes: Same as figure $1 ; b$ is the debt share of investment financing.

deductibility of nominal interest, the capital stock corresponding to a constant real after-tax discount rate would start to increase as inflation increased past 9 percent.

Summers' paper differs from these graphs because his real discount rate involves the real capital gains tax on individual share-owners, which rises linearly with inflation. In his simulations, the discount rate increases approximately two-tenths of a point for every eight points of inflation. If the capital gains tax were high enough, an increase in inflation would always depress investment. This turns out not to be the case for the parameters in the paper.

The taxation of nominal capital gains has a potent effect on investment. According to Summers' table 7, this nonneutrality alone could cause a 
10.6 percent fall in the capital stock when inflation jumps from zero to 8 percent. There are two reasons why this effect may be overstated. First, the effective capital gains rate is a decreasing function of inflation because the ratio of realizations to accruals falls with inflation. Second, the size of the adjustment costs add to the effect of the capital gains tax. Inflation causes nominal capital gains not only on the capital equipment but also on the inframarginal rents that accrue from the "right" to accumulate capital goods. In the simulations these rents are very large, as suggested by the difference noted above between the marginal and average costs of adjustment. To the extent that these rents are overestimated, the effect of the capital gains nonneutrality is overstated.

The final source of nonneutrality is the payment of extra taxes because of FIFO inventory accounting. Inventories are not explicitly modeled; the effect of FIFO is approximated as an increase in the corporate tax rate of about $1 \frac{1 / 3}{3}$ points for every point of inflation.

To count FIFO as a tax-cum-inflation deterrent of investment seems dubious. First, these extra taxes are voluntary. Second, if managers continue to use FIFO because they are as yet unaware of the extra taxes they are incurring, then this illusion should extend to whatever effects FIFO might have on their investment decisions. Third, in the long run-and this paper is about the long run-all firms will switch to LIFO given the large costs (five-hundred-dollar bills on the sidewalk) of doing otherwise. Fourth, even if FIFO accounting were required, the connection between plant and equipment decisions and taxes due to inventory profits is tenuous. These taxes might decrease inventory investment, to be sure, but why plant and equipment rather than labor input?

The effect of inflation is to reduce the value of the tax deduction for the costs of goods sold, which are wages and material costs. Treating the corporate sector as Summers does, as composed of identical competing vertically integrated firms, costs of goods sold are essentially just wages. Thus the extra taxes due to nominal inventory profits are a tax on the variable lagged input, labor, not on capital. Cost of goods sold is to labor and materials input what historical cost depreciation is to capital input. In Summers' economy labor is inelastically supplied and the only effect FIFO taxes can have is to reduce real wages. The mystery in the model, however, remains; why has not competition forced all firms to adopt LIFO? 
The same points made above concerning historical cost depreciation apply to FIFO. The FIFO tax loss increases with inflation in a nonlinear fashion and is bounded by the tax value of the deduction of variable input costs. If some fixed proportion of the value of inventories is financed through short-term debt, at high rates of inflation the value of the interest deductions associated with this debt will exceed the loss due to FIFO.

The results of the paper are extremely sensitive, not only in magnitude but in direction, to the assumption that share-owners' after-tax required real rate of return is constant. Incidentally, this assumption stands in contrast to the constant before-tax real interest rate assumed on corporate debt. A fall in the required rate of return of 20 basis points offsets the effect of inflation via capital gains tax. A fall of 50 basis points entirely offsets the effects of 8 percent inflation (aside from FIFO tax payments).

Thus even a small elasticity of the rate of return with respect to the quantity of capital would mitigate the large reductions in the steady-state capital stock that the simulations predict. But the issue is not really the slope of savers' supply of equity but rather whether the whole schedule shifted during the 1970s. The evidence that it has includes the fact that the real tax-exempt bond rate, even if corrected for changes in the applicable marginal tax rate implicit in the rate differential from Aaa corporate bonds, fell by at least 3 points during the past decade while inflation rose by 7 points.

Summers rationalizes his assumption of an unchanged discount rate somewhat differently. Perhaps somewhere in the world there is an asset whose return sets the opportunity cost for corporate capital. Evidently this asset cannot be debt. He suggests that it is housing, especially owneroccupied housing, whose favorable tax treatment is enhanced by inflation. But no crowding out of fixed investment by housing shows up in the figures. The boom year of 1979 was a big year for nonresidential investment but a very poor year for housing construction. In 1972 dollars housing was only 4 percent of GNP, compared to 4.5 to 5 percent at earlier cyclical peaks.

The assumption of a constant required rate of return is both important and dubious. It may be true that the rate of return required by equity investors has been increased by perceptions of higher macroeconomic risk, a hypothesis suggested near the start of these comments. But this is quite a different theory of the behavior of the stock market and investment 
from the tax and inflation explanation espoused in this paper, and in earlier influential papers by Feldstein and Summers together and individually.

It was fun to work on this paper, and our comments show that it can generate a lot of interest. The paper is impressive in both substance and method. More can be done in the same spirit.

\section{General Discussion}

Several panelists recommended caution in drawing policy conclusions from Summers' results. William Nordhaus noted the sensitivity of Summers' results to estimates of the effective capital gains tax rate. He reported that calculations of that rate based on a comparison of estimates of nominal capital gains on private assets from national wealth accounts and actual payments indicate a much smaller rate than that calculated by Summers. Summers' assumption of a constant after-tax real rate of return on equity and the implicit very high interest elasticity of savings available to the corporate sector drew considerable comment. Franco Modigliani said that, unfortunately, theoretical models provide very little guidance about the elasticity of saving because the income and substitution effects of higher interest rates operate in opposite directions. Indeed, a priori he found nothing implausible about a zero or negative elasticity with respect to interest rates. Although empirical estimates of the elasticity are not very reliable, Modigliani believed the preponderance of evidence places it near zero. Summers responded that, whatever the elasticity of total saving, the elasticity of funds to the corporate sector should be high. He agreed, however, that his analysis is more suitable for changes in the investment tax credit, most of which applies to the corporate sector, than for changes in the taxation of capital gains, most of which accrue to the noncorporate sectors of the economy. Modigliani questioned whether the effects of inflation on capital formation are accurately captured in a model that assumes the market fully understands the tax and distributional effects of inflation. He noted that his own work with Cohn suggests that the market has been badly confused, effectively treating nominal interest rates as if they were real.

Robert Hall discussed the theoretical and empirical issues raised by the fact that firms and stockholders voluntarily pay taxes they could 
avoid by changing their accounting or financial practices. Hall asserted that voluntary taxes are not consistent with Summers' assumption that firms maximize stockholders' after-tax returns. In the absence of a satisfactory explanation of why firms pay taxes they could avoid by converting to LIFO inventory valuation, or pay dividends that are not deductible at the corporate level but are taxable as ordinary income to stockholders, he suggested that Summers should not push some of his results too hard. Hall was particularly skeptical of Summers' result that the dividend tax rate has no effect on the long-run capital stock. He also agreed with James Tobin's skepticism about the effect of taxation of inventory profits on capital formation.

Robin Marris recalled his own model of the firm in which management maximizes its own utility rather than that of stockholders. It is similar to Summers' model in many respects, including the fact that firms would be almost entirely self-financed; but in contrast to Summers' model, taxes on dividends would have a substantial effect on investment and the growth rate.

Christopher Sims raised several questions about the empirical testing of the model. He did not find it surprising that Summers' investment equation performed poorly given the number of reasons one could expect variables in the equation to be subject to error and the possibilities for specification error. Some of these errors would lead to biases in particular coefficients. If, for example, the technology were putty-clay, one would expect fluctuations in $Q$ that would not be related to investment. This might explain the implausibly large estimates of adjustment costs mentioned by Tobin in his discussion. Sims gave several reasons why Summers' $Q$ may be endogenous and therefore why it is necessary to test for exogeneity. For example, shifts in the marginal product of capital may cause changes in $Q$; changes in investment demand and correlated changes in income may induce changes in the discount rate; and changes in tax policy itself may be prompted by changes in investment or income. The presence of any of these effects would require reinterpretation of Summers' results. Sims felt the tests that implicitly constrain the tax effects to work through $Q$ do not provide a powerful test of Summers' theory, because there are such a variety of models and assumptions that would give rise to a correlation of $Q$ and investment without necessarily implying a causative role to taxes themselves. 